This is a pre-print of an article published in Analytical and Bioanalytical Chemistry. The final authenticated version is available online at:

https://dx.doi.org/10.1007/s00216-020-02616-6 


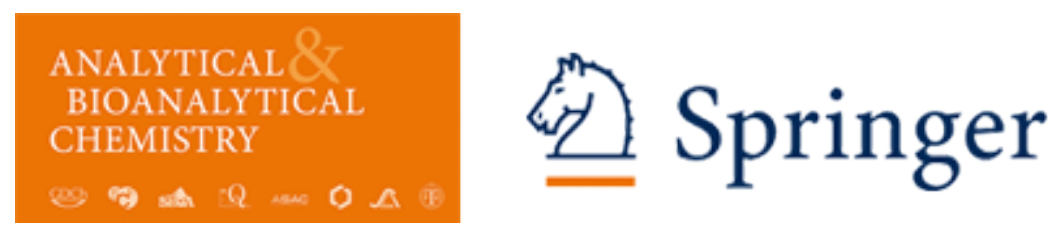

\section{A compact plasmonic biosensor device for the rapid and efficient monitoring of gluten free diet directly in human urine}

\begin{tabular}{|r|l|}
\hline Journal: & Analytical and Bioanalytical Chemistry \\
\hline Manuscript ID & Draft \\
\hline Type of Paper: & Research Paper \\
\hline Author: & n/a \\
\hline Complete List of Authors: & $\begin{array}{l}\text { Pelaez, E. Cristina; Institut Català de Nanociència i Nanotecnologia ICN2, } \\
\text { CSIC and CIBER-BBN, Nanobiosensors and Bioanalytical applications } \\
\text { Estevez, M.-Carmen; Institut Català de Nanociència i Nanotecnologia } \\
\text { ICN2, CSIC and CIBER-BBN, Nanobiosensors and Bioanalytical } \\
\text { applications } \\
\text { Dominguez, Remedios ; Biomedal S.L } \\
\text { Sousa, Carolina; University of Seville Faculty of Pharmacy, Department } \\
\text { of Microbiology and Parasitology } \\
\text { Cebolla, Angel; Biomedal S.L } \\
\text { Lechuga, Laura; Institut Català de Nanociència i Nanotecnologia ICN2, } \\
\text { CSIC and CIBER-BBN, Nanobiosensors and Bioanalytical applications }\end{array}$ \\
\hline Keywords: & $\begin{array}{l}\text { POC device, Gluten Immunogenic Peptides, 33-mer gliadin peptide, } \\
\text { celiac disease, urine, gluten-free diet }\end{array}$ \\
\hline & \\
\hline
\end{tabular}

\section{SCHOLARONE ${ }^{m}$




\title{
A compact plasmonic biosensor device for the rapid and efficient monitoring of gluten free diet directly in human urine
}

\author{
E. Cristina Peláez ${ }^{\mathrm{a}}$, M.-Carmen Estevez ${ }^{\mathrm{a}^{*}}$, Remedios Domínguez ${ }^{\mathrm{b}}$, Carolina Sousa ${ }^{\mathrm{c}}$, Angel Cebolla $^{\mathrm{b}}$ \\ and Laura M. Lechuga ${ }^{\mathrm{a}}$
}

a Nanobiosensors and Bioanalytical Applications Group, Catalan Institute of Nanoscience and Nanotechnology (ICN2), CSIC, CIBER-BBN and BIST, Campus UAB Bellaterra, 08193 Barcelona, Spain.

b Biomedal S.L., Polígono Industrial Parque Plata, c/ Calzada Romana 40, 41900 Camas, Seville, Spain.

c Department of Microbiology and Parasitology, Faculty of Pharmacy, University of Seville, c/Profesor García González, S/N, 41012 Seville, Spain

*Corresponding author: M.-Carmen Estevez: mcarmen.estevez@icn2.cat

\begin{abstract}
Celiac disease (CD) is a chronic autoimmune disorder induced in genetically susceptible individuals by the ingestion of gluten from wheat, rye, barley or certain varieties of oats. A careful diet follow-up is necessary to avoid health complications associated with long-term gluten intake by the celiac patients. Small peptides (GIP, gluten immunogenic peptides) derived from the gluten digestion, which are excreted in the urine and feces, have emerged as promising biomarkers to monitor gluten intake. We have implemented a simple and sensitive label-free point-of-care (POC) device based on Surface Plasmon Resonance for the direct detection of these biomarkers in urine. The assay employs specific monoclonal antibodies and has been optimized for the detection of the 33-mer $\alpha 2$-gliadin, known as the main immunogenic peptide of wheat gluten, and for the detection of GIP. Direct detection in undiluted urine has been accomplished by using biosensing chips containing a robust and stable biorecognition layer, obtained after carefully optimizing the biofunctionalization protocol. Excellent Limits of Detection have been reached $\left(1.6-4.0 \mathrm{ng} \mathrm{mL}^{-1}\right)$, which ensures the detection of gluten peptides even when the gluten intake is around the maximum tolerable amount in the digestive tract $(<50 \mathrm{mg})$ for celiac individuals. No sample pretreatment, extraction, or dilution is required, and the analysis takes less than $15 \mathrm{~min}$. The assay has been validated with real samples. These features pave the way towards an end-user easy-to-handle biosensor device for the rapid monitoring of gluten free diet (GFD) and the follow-up of the health status in celiac patients.
\end{abstract}

Keywords: POC device; Gluten Immunogenic Peptides; 33-mer gliadin peptide; Celiac disease; urine; Gluten-free diet 


\section{Introduction}

Celiac disease (CD) is an autoimmune enteropathy that leads to the destruction of the villi lining the small intestine. It is triggered by the ingestion of gluten-containing cereals in genetically predisposed individuals [1]. CD causes severe symptoms including chronic diarrhea, fatigue, abdominal distension, weight loss and also anaemia, osteoporosis and neurological symptoms due to malabsorption of nutrients $[2,3]$. The prevalence is approximately $1 \%$ worldwide but varies greatly in different geographical areas [4,5]. It is estimated that the number of undiagnosed cases is even higher [6,7]. Moreover, an increasing incidence of $\mathrm{CD}$ is observed, which can be partially attributed to the improvement in diagnostic techniques and disease awareness [8].

Gluten refers to a heterologous group of proteins composed of prolamin and glutelin fractions. The prolamin fraction known as gliadin contains the main toxic components [3]. Once consumed, gluten is partially digested into gliadin peptides (10 to 50 amino acids), which are resistant to degradation by intestinal proteases of the epithelial barrier of the intestinal mucosa [9]. These peptides are deaminated by enzyme tissue transglutaminase (tTG) converting them into more immunogenic molecules that activate the adaptive immune system [1]. This response involves antigen-presenting cells (APC) that express the haplotypes HLA-DQ2 and DQ8, the main genetic predisposition factor that triggers an immune response against digested gluten $[10,11]$. The APC are highly reactive to gliadin-specific $\mathrm{T}$ cells, which produce a cascade of inflammatory mediators, resulting in a damage to the intestinal mucosa manifested as villous atrophy, characteristic of CD [1]. Currently there is no cure for CD and the only therapeutic treatment is a strict adherence to a gluten-free diet (GFD) in daily life $[12,13]$. One of the main problems nowadays related to maintaining a GFD is the presence of hidden gluten in food [14]. Approximately, more than half of commercially available food contains gluten from wheat, barley, rye or oats, including those products where it is used as thickener or binder [15]. According to the regulation Codex Alimentarius (CODEX STAN118-1979, revised in 2008) [16], the total level of gluten in gluten-free food does not exceed $20 \mathrm{mg} \mathrm{Kg}^{-1}$. Therefore, constant vigilance is always required as the adhesion to a strict diet with zero gluten intakes is almost impossible given its ubiquity, cross-contamination or the inadequate food labelling regulations $[12,17,18]$. As a result, persistent symptoms and enteropathy are common among celiac patients who are trying to follow a GFD. Specifically, research shows that $25-40 \%$ of adults with CD have persistent enteropathy after two years on a GFD. Children are thought to recover more quickly, and data suggest that 5-19\% of celiac children on a GFD may have persistent enteropathy despite treatment with a GFD for at least one year. Moreover, the amount of gluten that celiac patients can tolerate has not yet been established due to the variability between individuals [18]. However, the effects of low gluten consumption in celiac patients have suggested that daily consumption of up to 50 mg can cause significant damage in the small intestine [19]. Hence, a daily intake of gluten less than 
$10 \mathrm{mg}$ is recommended to be safe and unlikely to cause significant abnormalities or to trigger symptoms [6].

Currently, several companies have commercialized detection assays such as Quanta Flash ${ }^{\circledR}$ Celiac (Werfen Company, Spain), Alegria ${ }^{\circledR}$ (Orgentec Diagnostika, Germany), EliA ${ }^{\mathrm{TM}}$ Celikey (tTG) / EliA $^{\text {TM }}$ Gliadin (Thermo Scientific Phadia, USA) and Anti-Gliadin GAF-3X ELISA / Anti-tTG ELISA (Euroimmun, Germany) to diagnose celiac disease, and iVYLISA GIPTM (Biomedal, Spain) to monitor the adherence to the GFD. They are commonly based on solid-phase immunoassays (i.e. ELISA, chemiluminescence and immunofluorescence) performed with bench-top, high throughput instruments. They are sensitive and specific tools, although are also considerably expensive. Their handling requires specialized skills and commonly these analysis are done in central laboratories and research centers. However, their location in primary healthcare settings is more limited and definitely less accessible to the patient himself [18,20-22].

The development of portable, compact and easy-to-handle tools entails significant advantages for its self-use by patients, as it allows direct detection or personalized monitoring of therapies usually with a small amount of a biological sample. Such is the case of the qualitative tests based on lateral flow immunochromatography (LFT) Sintomax ${ }^{\circledR}$ (Augurix SA, Switzerland), Xeliac ${ }^{\circledR}$ Test (Eurospital, Italy), and Biocard ${ }^{\mathrm{TM}}$ celiac test (AniBiotech ${ }^{\circledR}$, Vantaa, Finland) [22-25]. These companies have developed qualitative, direct, rapid and easy tests that support the monitoring or the diagnosis of the disease by the end-user. However, the limitation of these tests is mainly related to the lack of quantification of the analyte concentration to know the evolution of the immune response to treatment. In other instances (i.e. GlutenDetect ${ }^{\circledR}$, Biomedal, Spain), the sensitivity might not be enough to detect small intakes of gluten, and the use of additional cocktails for dilution and pretreatment of samples complicate the steps done by the user and restrict its continuous use at home.

We have designed a compact, portable and easy-to-use device based on Surface Plasmon Resonance (SPR) biosensing that overcomes the limitations mentioned above, to specifically and quantitatively monitor gluten intake levels from a simple urine analysis. The device is based on immunoassays similar to the ones used in the iVYCHECK GIP Urine ${ }^{\mathrm{TM}}$ test (Biomedal, Spain), where gluten immunogenic peptides (GIP), originated after gliadin degradation, are detected in urine and feces samples using highly specific monoclonal antibodies (mAb). These antibodies (G12 and A1) have a high affinity for GIP, especially for the $\alpha 2$-gliadin 33-mer peptide (MW $3.9 \mathrm{kDa}$ ), a small-sized and digestion-resistant peptide, which is the most immunodominant toxic peptide to the celiac patients $[18,22]$. A customized biofunctionalization strategy has been precisely established, successfully providing the direct, quantitative analysis of whole urine. No previous extraction, pretreatment or even dilution step is needed. The assays are implemented in a compact biosensor prototype, showing excellent levels of detection with both specific antibodies and wide dynamic ranges that allow detecting minimum concentrations of GIP for a strict GFD or low gluten intake. 


\section{Materials and Methods}

\section{Urine sample collection}

Two different types of urine samples were collected according to the donor's gluten-containing diet. Group 1 samples are obtained from celiac disease patients and healthy volunteers on strict gluten-free diet (GFD) and were used during the optimization and assessment of immunoassays. Group 2 samples are collected from healthy individuals following an unrestricted normal gluten-containing diet. The a2-gliadin 33-mer peptide concentrations were analysed with the iVYCHECK GIP Urine ${ }^{\mathrm{TM}}$ lateral flow device and quantified with the iVYCHECK GIP Reader ${ }^{\mathrm{TM}}$ from Biomedal S.L. (Seville, Spain) [17]. All volunteers were provided with sterile falcons $(50 \mathrm{~mL})$. Urine samples were collected and stored at $-20^{\circ} \mathrm{C}$. Written consent was obtained from all volunteers that provided samples.

\section{POC device and detection assay format}

The plasmonic biosensor device involves a miniaturized platform $\left(20 \times 20 \mathrm{~cm}^{2}\right)$ (see Fig.1) which incorporates the optical setup, the biosensor chip and the flow cell to bring samples over the sensing area. The sensor chips consist of a gold thin layer (1 nm Ti / $49 \mathrm{~nm} \mathrm{Au}$ ) evaporated on glass substrates. Additional external components, which can be further integrated such as input light source and spectrometer, are also incorporated. For a detailed description of the biosensor device and working principle, please refer to the Supplementary Information (SI). Briefly, the device tracks in real time the shift of the resonance peak $\left(\Delta \lambda_{\mathrm{SPR}}\right)$ of the gold sensor chip which arises when refractive index changes occur its surface, which are originated after binding or desorbing events occurs (see Fig $\mathrm{S} 1 \mathrm{~B}$ in SI). Thus, the sensing is direct and label-free. The selected detection assay is based on an indirect competitive immunoassay, where a similar compound of the target analyte (i.e. competitor) is immobilized on the sensor surface and competes with the analyte for the binding of a fixed concentration of the specific antibody (see Fig. 2 for a representative scheme of the assay). In this way, the concentration of analyte is inversely proportional to the signal observed, being maximum at zero analyte concentration. The competitor in this case was the prolamin working group (PWG) gliadin, which contains the epitopes the antibody is specific for. A covalent attachment of the PWG gliadin was selected.

\section{Sensor chip biofunctionalization and assay development}

Details on the chemical and immunochemical reagents and buffers are summarized in the SI. The formation of a self-assembled monolayer (SAM) onto the sensor chip surface was carried out using HS-C11-(EG) $6-\mathrm{O}-\mathrm{CH}_{2}-\mathrm{COOH}(1 \mathrm{mM})$ after overnight incubation at room temperature. Then, sensor chips were rinsed with ethanol and dried with a $\mathrm{N}_{2}$ stream. Biofunctionalization procedure was performed in-situ in order to optimize the immobilization conditions. Carboxylic groups of thiols 
were activated with a solution of 3(3-dimethylaminopropyl)carbodiimide hydrochloride (EDC), Nhydroxysulfosuccinimide (NHS) (EDC/NHS, $0.2 \mathrm{M} / 0.05 \mathrm{M}$ ) in MES buffer in a flow rate of $20 \mu \mathrm{L}$ $\mathrm{min}^{-1}$. A solution of PWG gliadin $\left(50 \mu \mathrm{g} \mathrm{mL}^{-1}\right)$ in acetate buffer $\mathrm{pH} 5.0$ was injected after activation at a flow rate of $10 \mu \mathrm{L} \mathrm{min}^{-1}$. Then, the remaining unreacted carboxylic groups were deactivated with a solution of $1 \mathrm{M}$ ethanolamine $\mathrm{pH} 8.5$ at a flow rate of $30 \mu \mathrm{L} \mathrm{min}-1$ for 2 min (see Fig. 2). An ex-situ immobilization was also used to generate the sensor chips for routine-based analysis following the optimized conditions. In this case, for the activation step, $200 \mu \mathrm{L}$ of the EDC/NHS solution was dropped over the SAM-functionalized sensor chips $(20 \mathrm{~min})$, followed by the overnight incubation at $4{ }^{\circ} \mathrm{C}$ with PWG gliadin (50 $\left.\mathrm{g} \mathrm{mL}^{-1}\right)$ and the ethanolamine deactivation step ( $\left.2 \mathrm{~min}\right)$. In between each step, sensor chips were rinsed with Milli-Q water and dried with a stream of $\mathrm{N}_{2}$. Chips were mounted on the optical device and kept in a continuous flow of PBST buffer at $25 \mu \mathrm{L} \mathrm{min}{ }^{-1}$ before measurements.

A fixed concentration of each monoclonal antibody was chosen after performing non-competitive assays (i.e. in the absence of analyte) over PWG gliadin-biofunctionalized sensor chips: G12 mAb (2 $\left.\mu \mathrm{g} \mathrm{mL}^{-1}\right)$ and $\mathrm{A} 1 \mathrm{mAb}\left(5 \mu \mathrm{g} \mathrm{mL}^{-1}\right)$. The antibody concentration was selected so that (i) it enabled the analysis under non-saturation conditions in PBST buffer and (2) the signal was high enough to allow monitoring a broad range of analyte concentrations (data not shown). A stock solution of target $\alpha 2-$ gliadin 33-mer peptide (1 $\mathrm{mg} \mathrm{mL}^{-1}$ in PBS) was used to prepare the standards to obtain the calibration curve (from $0.1 \mathrm{ng} \mathrm{mL}^{-1}$ to $4.0 \mu \mathrm{g} \mathrm{mL}^{-1}$ in PBST buffer) using both antibodies. The incubation time between the antibody and the analyte was set to $15 \mathrm{~min}$ at room temperature. Sample containing the antibody-analyte mixture was then flowed through the sensor chip at a flow rate of $25 \mu \mathrm{L} \mathrm{min}{ }^{-1}$. Free antibodies not bound to the 33-mer peptide in solution can then interact with the immobilized PWG gliadin. Total dissociation of the antibody-PWG gliadin interaction was efficiently accomplished by injecting a $5 \mathrm{mM} \mathrm{NaOH}$ solution during $120 \mathrm{~s}$. Calibration curves for the 33-mer peptide detection were obtained. The average $\left(\Delta \lambda_{\mathrm{SPR}}\right)$ and standard deviation (SD) of triplicate analysis were graphed and the data were adjusted to a dose-response inhibition equation, as described elsewhere [26,27]. The analytical parameters as Limit of Detection (LOD), the half inhibitory concentration $\left(\mathrm{IC}_{50}\right)$, and the dynamic range (the interval between $\mathrm{IC}_{80}-\mathrm{IC}_{20}$ ) were calculated. Intra-assay (two calibration curves obtained with the same biofunctionalized sensor chip) and inter-assay (three calibration curves obtained with three different biofunctionalized sensor chips) variability was assessed.

\section{Analysis of urine samples}

The effect of urine on the assay performance (i.e. nonspecific adsorption) was removed by adding a blocking layer consisting of BSA $10 \mathrm{mg} \mathrm{mL}^{-1}$ diluted in PBST. This solution was injected over the sensor chip for 2 min right before the injection of each urine sample. The conditions to achieve full removal of nonspecific adsorptions from urine are summarized in the SI. Control experiments related 
to the effect of urine were done with urine collected from Group 1 donors (i.e. adhered to a GFD and therefore, with no 33-mer peptide present). The effect of urine in the assay was evaluated with calibration curves generated using $\alpha 2$-gliadin 33-mer peptide standards prepared in urine from Group 1 donors. Additional calibration curves were obtained for GIP instead of only 33-mer peptide by using real urine sample containing digested GIP. The GIP concentration of this urine sample was previously quantified with the lateral flow test iVYCHECK GIP Urine ${ }^{\mathrm{TM}}$ and the iVYCHECK GIP Reader ${ }^{\mathrm{TM}}$. The sample was subjected to a preconcentration step using centrifugal filters Amicon Ultra $10 \mathrm{kDa}$ to obtain a stock GIP solution of known concentration. Then, a set of serial dilutions at different concentrations of GIP were prepared with Group 1 urine as solvent and analyzed with each monoclonal antibody. Finally, 21 patient samples from Group 2 donors were directly analyzed with the biosensor and the concentration of GIP calculated from the calibration curves. The results were compared with those values determined with the commercial detection assay (iVYCHECK GIP Urine $^{\mathrm{TM}}$, Biomedal) and expressed as \% Recovery:

$$
\text { Recovery, } \%=\frac{[\text { GIPS }]_{S P R}}{\left[\text { GIPS }_{\text {iVYCHECK }} \text { GIP Urine }^{\mathrm{tm}}\right.} \times 100
$$

Those urine samples whose concentration fell below the LOD were preconcentrated before analysis using the centrifugal filters Amicon Ultra $10 \mathrm{kDa}$. Samples whose concentration was above the dynamic range required additional dilution using Group 1 urine. All samples were analyzed in triplicate.

\section{Results and discussion}

Bringing diagnostics close to the primary care or to the patient itself requires simple, yet sensitive, fast and direct analysis of a readily extracted sample. Urine sample is ideal however its direct detection is not always possible depending on the detection assay. Manipulation of the sample to obtain a reliable signal commonly involves sample pre-treatment or dilution at best, eventually affecting the sensitivity required and moving away from the concept of point-of-care. Our detection assay is based on an indirect competitive assay performed on a label-free optical device and we have newly customized the sensing chip biofunctionalization to facilitate the direct addition in urine and to extend the half-life of the biosensing chips.

\section{Immunoassay development}

Two monoclonal antibodies (G12 and A1) with a high affinity for 33-mer peptide have been considered for the assay development. They show reactivity to different prolamin epitopes from wheat, barley, rye and some oat varieties. The G12 mAb recognizes QPQ-(L/Q)-P-(Y/F) and A1 mAb reacts against the epitopes $\mathrm{Q}-(\mathrm{Q} / \mathrm{L})-\mathrm{P}(\mathrm{Y} / \mathrm{F})-\mathrm{PQP}$. Both antibodies are currently used in research, food analysis and clinical monitoring of CD and implemented in commercial assays such as ELISA and LFT for the detection of GIP excreted in human feces and urine [22,28-30]. For the indirect 
competitive assay, PWG gliadin (MW 33 to $45 \mathrm{kDa}$ ), which contains the epitopes the antibody is specific for, is immobilized on the sensor chip surface at a fixed concentration and competes with the free 33-mer peptide (or the family of GIP in a real sample) for the binding of the monoclonal antibodies (G12 or A1) (see Fig. 2). To facilitate the attachment of PWG gliadin, a self-assembled monolayer (SAM) with reactive groups (-COOH group) was added to the gold sensor chip.

Contrary to the use of conventional aliphatic thiolated compounds (i.e mercaptoundecanoic acid or mercaptohexadecanoic acid), in this case we have selected thiol groups containing ethylene glycol units in their structure in order to prevent non-specific adsorptions from the urine matrix [31,32]. A reactive compound $\left(\mathrm{HS}-\mathrm{C}_{11}-(\mathrm{EG})_{6}-\mathrm{O}-\mathrm{CH}_{2}-\mathrm{COOH}\right)$ and an inert one (HS- $\left.\mathrm{C}_{11}-(\mathrm{EG})_{4}-\mathrm{OH}\right)$ used as lateral spacer to spread the PWG gliadin on the sensor chip surface were initially selected. Parameters such as SAM composition at different $\mathrm{COOH}: \mathrm{OH}$ molar ratios $(3: 7,1: 1,7: 3$ and 1:0) and suitable buffer to attach the PWG gliadin $\left(50 \mu \mathrm{g} \mathrm{mL}^{-1}\right)$ were tested (see Fig. S2A in SI). Those conditions resulting in higher PWG gliadin immobilization signal $\left(\Delta \lambda_{\mathrm{SPR}} 12.7 \pm 1.5 \mathrm{~nm}\right)$ were selected (SAM ratio $\mathrm{COOH}: \mathrm{OH}$ 1:0 -no spacers- and acetate buffer $\mathrm{pH} 5.0$ for PWG gliadin immobilization). According to the results obtained, acid $\mathrm{pH}$ (between $\mathrm{pH} 4.0$ and 5.5) can improve considerably the immobilization signal due to the electrostatic interactions between the SAM layer and the PWG gliadin (i.e. it increases the local concentration of PWG gliadin on the surface, resulting in a more efficient coupling yield). Fig. S2B in SI shows a real-time sensorgram of an in-situ immobilization for the selected conditions. Then, the in-situ immobilization was adapted to an ex-situ strategy, with the aim of generating enough sensor chips to perform routine analysis and to study their stability over time. The same signal for the antibody detection was virtually obtained over gliadin coated sensor chips functionalized via either the in-situ or the ex-situ protocol (i.e. $\Delta \lambda_{\mathrm{SPR}} 1.2 \pm 0.1$ for G12 mAb and $1.0 \pm 0.1$ for $\mathrm{A} 1 \mathrm{mAb}$, see Fig. S2C in SI), confirming that both procedures were equally effective and that the biofunctionalization is stable and reproducible. The optimal concentration of antibodies was determined by non-competitive assays. Moreover, the total dissociation of the PWG gliadin-antibody interaction was guaranteed using $\mathrm{NaOH} 5 \mathrm{mM}$ without damaging gliadin integrity, allowing the repeated use of the sensor chip. The recognition layer was viable for at least 20 cycles of interactions with G12 mAb and 32 cycles with A1 mAb (see Fig. S3A and B in SI, respectively). Under these conditions, calibration curves using both antibodies were obtained by measuring different 33-mer peptide concentrations.

Fig. S4 in SI shows two representative calibration curves using both mAbs and different 33-mer peptide concentrations in PBST buffer. Table S1 in SI, shows the analytical parameters of the curves. The LOD using G12 mAb is around one order of magnitude lower than A1 mAb (i.e $\sim 2 \mathrm{ng} \mathrm{mL}^{-1}$ and $\sim 20 \mathrm{ng} \mathrm{mL}^{-1}$, respectively). Also, the sensitivity reflected in the $\mathrm{IC}_{50}$ values is more than one order of magnitude better for G12 mAb assay. Nevertheless, the dynamic range for the assay with $\mathrm{A} 1 \mathrm{mAb}$ is wider compared with the one obtained with $\mathrm{G} 12 \mathrm{mAb}$, as a direct consequence of its lower slope (i.e. 
$\sim-1.4$ for G12 mAb assay and -1 for A1 mAb assay), which extends the measurement range. This eventually can be an advantage as a higher number of real samples may fall within this range and, therefore, this increases the assay capabilities. The intra- and inter-assay evaluation confirms the high reproducibility and stability of the immunoassays in the same sensor chip or in different sensor chips, especially in the case of the G12 assay. Fig. S5A and B in SI, shows representative sensorgrams obtained for different 33-mer peptide concentrations for both G12 and A1 assays which exemplifies the low level of noise of the signals for each measurement.

\section{Effect of the urine in the assay performance}

Urine, as any other human fluids, can affect the immunoassays, as it is commonly reported $[26,33]$, either by hindering the interaction between the receptor and the target or by the non-specific adsorption of some of its components on the sensor surface. This eventually results in worst assay performance, being necessary the implementation of sample pretreatment or dilution steps. To minimize or avoid any of these undesired effects, we have employed thiols containing ethylene glycol units in their structure (EG-thiols) [31]. The generation of this ethylene glycol layer did not however completely remove non-desired adsorptions when analyzing pure urine (see red sensorgram in the Fig. $3 \mathrm{~A}, \lambda_{\mathrm{SPR}} \sim 0.5 \mathrm{~nm}$ ) or even after diluting urine $50 \%$ (blue sensorgram in Fig. $3 \mathrm{~A}, \lambda_{\mathrm{SPR}} \sim 0.25 \mathrm{~nm}$ ). Nevertheless, introducing an extra blocking step consisting of BSA (10 $\mathrm{mg} \mathrm{mL}^{-1}$ in PBST) for $2 \mathrm{~min}$ before each urine sample analysis, resulted in the formation of an extra layer (as evidenced by the resultant positive signal of $\Delta \lambda_{\mathrm{SPR}}$ around $0.12 \pm 0.02 \mathrm{~nm}$, see Fig. S6.A) with antifouling properties which completely suppressed any kind of adsorptions derived from urine (see Fig. 3A, green and orange sensorgrams for $50 \%$ and urine $100 \%$, respectively, where $\Delta \lambda_{\mathrm{SPR}} \sim 0$ ). The experimental conditions of this extra step were precisely optimized to achieve maximum efficiency (see SI for detailed description and Fig. S6 therein). Moreover, under these conditions, the addition of BSA did not seem to affect the interaction of the antibody with the PWG gliadin layer, as signals for both G12 and A1 antibodies remained the same as can be checked in Fig 3B. The regeneration and reusability of such sensor surfaces were similarly assessed, and a slightly higher deterioration was observed compared with PBST measurements (see SI and Fig. S6 therein). Nevertheless, it was still possible to have active sensor surfaces for around 15-17 cycles, for both G12 and A1 antibodies.

Complete calibration curves prepared directly in urine $100 \%$ indeed demonstrate that the developed strategy do not affect at any level the assay performance compared with 50\% urine or in PBST (see Fig. 3C and D, for calibration curves with G12 and A1 antibodies, respectively, and Table 1 for a summary of the assays analytical features). As can be observed, the differences are minimal and the curves look analogous. The $\mathrm{LOD}$ and $\mathrm{IC}_{50}$ are very similar for both 100 and $50 \%$ urine, which confirm the excellent effect that the extra blocking with BSA causes regarding the removal of any interference. A slight variation in the LOD and in the slope of the assay is observed, compared with PBST buffer (i.e. it decreases as the amount of urine increases) which translates in broader working 
range when whole urine is analyzed although these differences are minimal, thus not hindering the attempt of directly analyzing real samples. Real-time sensorgrams for different 33-mer peptide concentrations incubated with both G12 and A1 antibodies are shown in Fig. S7A and B in SI.

\section{Selectivity of G12 and A1 mAb for GIP in real urine samples}

Previous studies have demonstrated the capability of G12 and A1 mAbs of recognizing other toxic immunogenic peptides generated from gluten (GIP) present in wheat, barley, rye and oats. The affinity however varies significantly depending on the epitope. From those studies, A1 showed a broader specificity that G12 [18,34]. After consumption of gluten from different origin, several GIP will be present in the patient's urine and their quantification might therefore be affected due to the recognition pattern of the antibody employed. Therefore, in order to mimic a real sample analysis, calibration curves with both antibodies were done using a mixture of GIP obtained from a real urine sample instead of single 33-mer peptide, applying the optimal conditions described above. Fig. 4 shows the calibration curves obtained in urine $100 \%$ using GIP with G12 mAb (purple) and A1 mAb (orange), which are compared with those obtained with 33-mer peptide for G12 mAb (blue) and A1 $\mathrm{mAb}$ (green). Calibration curves of 33-mer peptide and digested GIP obtained with G12 mAb (blue and purple lines) were very similar in terms of analytical parameters (see data summarized in Table 1). These results highlight the high specificity of the G12 mAb to directly measure the 33-mer peptide in urine in a set of gliadin-derived peptides without affecting the resulting average sensitivity. On the contrary, for the case of A1 antibody assays (green and orange calibration curves), although the LOD were similar, the $\mathrm{IC}_{50}$ was twice smaller when using GIP mixture, which reflects that the recognition pattern of this antibody indeed includes other peptides, maybe with even higher affinity than for 33mer peptide [35]. Also, using GIP as target analyte resulted in a more restricted dynamic range, but still broader than the one obtained with G12 mAb. These characteristics may eventually benefit the real sample analysis, by avoiding previous dilution in highly concentrated samples, for example. Nevertheless, in a more real scenario where the target analyte is a mixture of peptides, the assay using G12 mAb offers a better sensitivity for GIP than using A1 mAb. Besides, the coefficients of variability (CV) of key parameters of 33-mer and GIP immunoassays with G12 mAb, which are significantly improved (see Table S2 in SI) compared with the one obtained in PBST (shown in Table $\mathrm{S} 1$ in SI), proved the excellent reproducibility and great robustness of our plasmonic biosensor.

Moreover, for the case of G12 mAb based assay, our biosensor device offers a better performance than the semi-quantitative lateral flow test (iVYCHECK GIP Urine ${ }^{\mathrm{TM}}$ ) which relies on the use of A1 and G12 antibodies. This test is capable of detecting GIP in urine in the range of 6.48-100 $\mathrm{ng} \mathrm{mL}^{-1}$ although it requires a sample extraction or dilution pretreatment in order to isolate the peptides and/or to remove interferences $[22,36]$. Conversely, our biosensor can directly analyze the urine collected 
Table 1. Analytical parameters of all the competitive immunoassays in buffer and urine

\begin{tabular}{|c|c|c|c|c|c|c|}
\hline \multirow[t]{2}{*}{$\mathbf{m A b}$} & \multirow[t]{2}{*}{ Target } & \multirow[t]{2}{*}{ Sample } & $\begin{array}{c}\operatorname{LOD}\left(\mathrm{IC}_{90}\right) \\
\left(\mathrm{ng} \mathrm{mL}^{-1}\right)\end{array}$ & $\begin{array}{c}\mathrm{IC}_{50} \\
\left(\mathrm{ng} \mathrm{mL}^{-1}\right) \\
\end{array}$ & \multirow{2}{*}{$\begin{array}{c}\text { Working range } \\
\left(\mathrm{IC}_{80} / \mathrm{IC}_{20}\right)\left(\mathrm{ng} \mathrm{mL}^{-1}\right)\end{array}$} & \multirow[t]{2}{*}{ Slope } \\
\hline & & & Mean \pm SD & Mean \pm SD & & \\
\hline \multirow{4}{*}{ G12 } & 33-mer & PBST & $3.6 \pm 0.3$ & $14.4 \pm 1.6$ & $6.0 \pm 0.5 / 34.5 \pm 5.0$ & -1.566 \\
\hline & 33-mer & Urine-PBST 1:1 & $3.8 \pm 0.9$ & $18.3 \pm 3.2$ & $6.6 \pm 1.5 / 50.6 \pm 6.0$ & -1.290 \\
\hline & 33-mer & Urine $100 \%$ & $1.6 \pm 0.1$ & $15.2 \pm 2.2$ & $3.6 \pm 0.2 / 56.2 \pm 13.3$ & -0.869 \\
\hline & GIP & Urine $100 \%$ & $1.7 \pm 0.1$ & $11.6 \pm 0.6$ & $3.4 \pm 0.1 / 35.4 \pm 3.0$ & -1.114 \\
\hline \multirow{4}{*}{ A1 } & 33-mer & PBST & $12.7 \pm 0.5$ & $75.5 \pm 4.7$ & $23.5 \pm 0.7 / 256.7 \pm 26$ & -1.095 \\
\hline & 33-mer & Urine-PBST 1:1 & $8.9 \pm 1.6$ & $127.1 \pm 8.4$ & $23.7 \pm 1.9 / 610.5 \pm 47$ & -0.797 \\
\hline & 33-mer & Urine $100 \%$ & $4.7 \pm 1.3$ & $111.8 \pm 12.1$ & $14.7 \pm 3.2 / 702.3 \pm 110$ & -0.623 \\
\hline & GIP & Urine $100 \%$ & $4.0 \pm 1.1$ & $41.2 \pm 4.7$ & $9.1 \pm 1.2 / 172.1 \pm 43.3$ & -0.864 \\
\hline
\end{tabular}

(Mean value \pm SD for three replicates of inter-assays obtained in 3 different biofunctionalized chip).

\section{Sensor chip storage and stability}

The stability over time of the sensor chips were studied following a systematic optimization of several sensitive parameters (data not disclosed due to confidentiality). Under the optimal conditions of preparation, biofunctionalization and storage, we observed that the biofunctionalized sensor chips were stable for up to 6 months without affecting their integrity and functionality, as can be seen in Fig. S8 in the SI, where urine samples spiked with 33-mer peptide (at the corresponding $\mathrm{IC}_{50}$ concentration) were analyzed after different span times. As can be observed very similar signals were obtained for the two assays using either G12 or A1 antibodies (CV of $3.58 \%$ and $11.30 \%$ respectively), which is indicative of the excellent robustness and stability of our protocol for at least the evaluated period of time.

\section{Validation with real urine samples}

In order to evaluate the accuracy and reliability of the biosensor device, 21 urine samples collected from Group 2 donors (healthy volunteers who had previously ingested a certain amount of gluten) were analyzed with our plasmonic biosensor and the data compared with the results obtained with the iVYCHECK GIP Urine ${ }^{\mathrm{Tm}}$ test [22]. The signals were interpolated in both G12 and A1 mAb calibration curves of digested GIP. Each sample was measured three times obtaining the average, standard deviation and the recovery. Results are summarized in Table 2. The accuracy offered by our approach is excellent, with recovery values of $96-101 \%$ and $91-111 \%$ for both G12 and A1 antibody assays, respectively. The excellent correlation of our biosensor device with the iVYCHECK GIP Urine ${ }^{\mathrm{TM}}$ test can be seen also in the Fig. 5 with an almost perfect correlation (i.e. slope close to 1 in both cases: 0.96 for G12-based assay and 1.03 for A1 based assay). As can be seen in the correlation plot, for higher concentrations $\left(>80 \mathrm{ng} \mathrm{mL}^{-1}\right)$ a slight drift appears, with a tendency to 
increase the slope (i.e. overestimate) for the A1-based assay and with a trend to decrease the slope (i.e. underestimate) for the G12-based assay. These trends, however, are not that significant for the range of concentration evaluated. Moreover, the level of precision and reproducibility is also evident from the SD values observed for each of the samples. Overall, the performed validation corroborates the excellent features achieved with our biosensor approach, in terms of reproducibility, accuracy and precision for the quantification of GIP.

Table 2. Real samples validation of the plasmonic device

\begin{tabular}{lccccc}
\hline Sample & $\begin{array}{c}\text { iVYCHECK } \\
\text { GIP Urine }\end{array}$ & \multicolumn{4}{c}{ Plasmonic device } \\
\cline { 3 - 6 } & [GIP] $\left(\mathbf{n g} \mathbf{~ m L}^{-1}\right)$ & $\begin{array}{c}\text { G12-based assay } \\
\text { [GIP] }\left(\mathbf{n g} \mathbf{~ m L}^{-1}\right)\end{array}$ & $\begin{array}{c}\text { Recovery, } \\
\mathbf{( \% )}\end{array}$ & $\begin{array}{c}\text { A1-based assay } \\
\text { [GIP] }\left(\mathbf{n g} \mathbf{~ m L}^{-1}\right)\end{array}$ & $\begin{array}{c}\text { Recovery, } \\
\text { (\%) }\end{array}$ \\
\hline P1 & 19.10 & $19.2 \pm 1.1$ & $100.5 \pm 5.5$ & $21.2 \pm 1.0$ & $111.1 \pm 5.2$ \\
\hline P2 & 12.30 & $12.5 \pm 0.6$ & $101.4 \pm 4.6$ & $11.5 \pm 0.6$ & $93.7 \pm 4.7$ \\
\hline P3 & 24.10 & $23.5 \pm 1.1$ & $97.7 \pm 4.7$ & $26.7 \pm 0.5$ & $110.7 \pm 2.1$ \\
\hline P4 & 27.97 & $28.4 \pm 1.2$ & $101.7 \pm 4.3$ & $25.5 \pm 4.6$ & $91.2 \pm 16.4$ \\
\hline P5 & 12.80 & $12.6 \pm 0.2$ & $98.7 \pm 1.4$ & $12.3 \pm 0.4$ & $96.3 \pm 3.2$ \\
\hline P6 & 9.27 & $9.3 \pm 0.1$ & $100.5 \pm 1.2$ & $8.9 \pm 1.2$ & $95.8 \pm 2.3$ \\
\hline P7* & 130.6 & $126 \pm 5.0$ & $96.5 \pm 3.8$ & $136.2 \pm 1.1$ & $104.2 \pm 0.8$ \\
\hline P8 & 35.8 & $34.5 \pm 1.2$ & $96.4 \pm 3.5$ & $35.2 \pm 2.3$ & $98.3 \pm 6.3$ \\
\hline P9 & 25.9 & $26.2 \pm 0.4$ & $101.3 \pm 1.6$ & $26.3 \pm 0.9$ & $101.5 \pm 3.3$ \\
\hline P10 & 24.5 & $23.6 \pm 1.6$ & $96.3 \pm 6.7$ & $23.8 \pm 0.1$ & $97.2 \pm 0.6$ \\
\hline P11 & 14.2 & $14.0 \pm 0.5$ & $98.8 \pm 3.5$ & $14.3 \pm 1.0$ & $100.4 \pm 7.1$ \\
\hline P12 & 17.2 & $17.2 \pm 0.1$ & $100.2 \pm 0.5$ & $16.2 \pm 1.4$ & $94.2 \pm 8.2$ \\
\hline P13* & 7.4 & $7.2 \pm 0.2$ & $97.6 \pm 2.3$ & $8.0 \pm 1.2$ & $108.1 \pm 16.7$ \\
\hline P14 & 28.0 & $28.4 \pm 1.4$ & $101.4 \pm 4.9$ & $28.0 \pm 0.6$ & $100.1 \pm 2.2$ \\
\hline P15 & 21.9 & $21.7 \pm 0.5$ & $99.0 \pm 2.3$ & $21.6 \pm 0.8$ & $98.7 \pm 3.8$ \\
\hline P16* & 94.5 & $91.8 \pm 3.4$ & $97.1 \pm 3.6$ & $93.0 \pm 1.2$ & $98.4 \pm 1.3$ \\
\hline P17 & 17.7 & $17.4 \pm 0.3$ & $98.1 \pm 1.5$ & $17.2 \pm 0.1$ & $97.3 \pm 0.8$ \\
\hline P18 & 32.5 & $32.9 \pm 0.6$ & $101.1 \pm 1.8$ & $34.4 \pm 2.1$ & $105.9 \pm 6.6$ \\
\hline P19 & 13.3 & $13.2 \pm 0.1$ & $99.4 \pm 1.1$ & $13.7 \pm 0.7$ & $103.2 \pm 5.3$ \\
\hline P20 & 15.6 & $15.3 \pm 0.4$ & $98.1 \pm 2.3$ & $15.7 \pm 0.7$ & $100.3 \pm 4.4$ \\
\hline P21 & 34.1 & $34.0 \pm 0.8$ & $99.8 \pm 2.3$ & $35.7 \pm 2.1$ & $104.8 \pm 6.2$ \\
\hline
\end{tabular}

${ }^{\mathrm{a}}$ Each value represents the mean $\pm \mathrm{SD}$ of triplicate measurements.

*Out of dynamic range (Sample P13 was preconcentrated and measured only with the A1 mAb assay. P7 and P16 were diluted five and four times respectively and measured with the G12 mAb assay.

\section{Evaluation of the biosensor device for low gluten intake diet follow-up}

We have performed a quantitative test to monitor the consumption of gluten in diet. The G12 based assay was selected because its lower limit of quantification ( $\mathrm{LOQ}=\mathrm{IC}_{80}$ of $3.4 \mathrm{ng} \mathrm{mL}-1$ ) compared with the A1 based assay $\left(9.1 \mathrm{ng} \mathrm{mL}^{-1}\right)$. Urine samples were collected from two healthy volunteers from Group 2, who had an uncontrolled gluten diet (UGD). Later, they started a supervised glutenfree diet for at least 36 hours. Between days $1(24 \mathrm{~h})$ and $2(48 \mathrm{~h})$, urine samples were collected to corroborate that the volunteers had adhered to a GFD for a sufficient time. In the next days, volunteers 


\section{Conclusions}

We have developed a plasmonic device that allows rapid, highly reproducible, accurate and noninvasive gluten intake control using a small amount of patient's urine $(200 \mu \mathrm{L})$. We demonstrate that with the explicitly designed biofunctionalization protocol, the plasmonic biosensor directly quantifies GIP generated after digestion of gluten and excreted in the urine. No extraction or any other type of sample pretreatment or purification is needed, which greatly simplifies the analysis and speeds up its implementation as an autonomous POC device that could be easily used by celiac patients to monitor their own adherence to GFD. Excellent levels of sensitivity and specificity are reached using two different monoclonal antibodies (G12 and A1) that show a different recognition pattern of GIP. In both cases the LODs achieved (around 1.7 and $4.0 \mathrm{ng} \mathrm{mL}^{-1}$ respectively), guarantee the detection of minimal quantities of GIP even after low gluten intake. This device shows exceptional reproducibility, reliability and accuracy, demonstrated in the correlation analysis with a significant number of real samples, reaching recoveries close to $100 \%$, which corroborates the feasibility and robustness of the biosensing method. So far, the biosensor chips show a promising storage stability of 6 months although further studies will cover a broader time span to ensure a storage capability in compliance with commercialized tests standards. Moreover, further integration of the biosensor chip in a disposable microfluidics cartridge will enable their integration and potential manufacturing. This biosensing strategy implemented in the plasmonic biosensor is highly attractive to monitor the treatment of celiac disease and to assess any potential infringement of a gluten-free diet, as it has been illustrated with the tracking of the GIP levels in two individuals subjected to a controlled gluten diet. Overall, the developed biosensor device holds great potential as a convenient sensing tool for the label-free non-invasive celiac disease follow-up, for promoting self-monitoring of celiac patients in the daily life and it reduces the need for additional invasive investigations on follow-up.

\section{Acknowledgments}


We acknowledge the financial support from URINETEST Project (Retos Colaboración URINETEST RTC-2016-5452-1). ICN2 is supported by the Severo Ochoa program from Spanish MINECO (Grant No. SEV-2017-0706).

\section{References}

[1] Green PHR, Lebwohl B, Greywoode R. Celiac Disease. Allergy Clin. Immunol. 2015;134:1099-1106.

[2] Comino I, Real A, De Lorenzo L, Cornell H, López-Casado MA, Barro F, Lorite P, Torres MI, Cebolla A, Sousa C. Diversity in oat potential immunogenicity: Basis for the selection of oat varieties with no toxicity in coeliac disease. Gut. 2011;60:915-22.

[3] Sharma GM, Pereira M, Williams KM. Gluten detection in foods available in the United States - A market survey. Food Chem. 2015;169:120-26.

[4] Bernardo D, Peña AS. Developing strategies to improve the quality of life of patients with gluten intolerance in patients with and without coeliac disease. Eur. J. Intern. Med. 2012;23:68.

[5] Valenti S, Corica D, Ricciardi L, Romano C. Gluten-related disorders: certainties, questions and doubts, Ann. Med. 2017;49:569-81.

[6] Castillo NE, Theethira TG, Leffler DA. The present and the future in the diagnosis and management of celiac disease. Gastroenterol. Rep. 2015;3:3-11.

[7] Esteve M, Rosinach M, Llordés M, Calpe J, Montserrat G, Pujals M, Cela A, Carrasco A, Ibarra M, Ruiz-Ramirez P, Tristán E, Arau B, Ferrer C., Mariné M, Ribes J, FernándezBañares F. Case-finding in primary care for coeliac disease: Accuracy and cost-effectiveness of a rapid point-of-care test. United Eur. Gastroenterol. J. 2018;6:855-65.

[8] Polanco I, Koester Weber T, Martínez-Ojinaga E, Molina M, Sarria J. Efficacy of a point-ofcare test based on deamidated gliadin peptides for the detection of celiac disease in pediatric patients, Rev. Esp. Enfermedades Dig. 2017;109:743-48.

[9] Garnier-Lengliné H, Cerf-Bensussan N, Ruemmele FM. Celiac disease in children, Clin. Res. Hepatol. Gastroenterol. 2015;39:544-51.

[10] Harris LA, Park JY, Voltaggio L, Lam-Himlin D. Celiac disease: clinical, endoscopic, and histopathologic review. Gastrointest. Endosc. 2012;76:625-40.

[11] Meresse B, Malamut G, Cerf-Bensussan N. Celiac Disease: An Immunological Jigsaw, Immunity. 2012;36:907-19.

[12] Jnawali P, Kumar V, Tanwar B. Celiac disease: Overview and considerations for development of gluten-free foods. Food Sci. Hum. Wellness. 2016;5:169-76.

[13] Jabri B, Sollid LM. T Cells in Celiac Disease, J. Immunol. 2017;198:3005-14.

[14] Stamnaes J, Sollid LM. Celiac disease: Autoimmunity in response to food antigen, Semin. 
Immunol. 2015;27:343-52.

[15] Moreno ML, Rodríguez-Herrera A, Sousa C, Comino I. Biomarkers to monitor gluten-free diet compliance in celiac patients. Nutrients. 2017;9:1-14.

[16] I.F.S. Codex Alimentarius, Standard for Foods for Special dietary Use for Persons Intolerant to Gluten CODEX STAN118-1979., Http://www.codexalimentarius.net. (2019). http://www.codexalimentarius.net (accessed February 13, 2019).

[17] Moreno ML, Cebolla A, Munõz-Suano A, Carrillo-Carrion C, Comino I, Pizarro A, León F, Rodríguez-Herrera A, Sousa C. Detection of gluten immunogenic peptides in the urine of patients with coeliac disease reveals transgressions in the gluten-free diet and incomplete mucosal healing. Gut. 2017;66:250-57.

[18] Comino I, Real A, Moreno ML, Montes R, Cebolla A, Sousa C. Immunological determination of gliadin 33-mer equivalent peptides in beers as a specific and practical analytical method to assess safety for celiac patients. J. Sci. Food Agric. 2013;93:933-43.

[19] Tommasini A, Not T, Ventura A. Ages of celiac disease: From changing environment to improved diagnostics. World J. Gastroenterol. 2011;17:3665-71.

[20] Leja M, Kojalo U, Frickauss G, Bandere B, Gavars D, Viesturs B. Changing patterns of serological testing for celiac disease in Latvia, J. Gastrointest. Liver Dis. 2011;20:121-26.

[21] Mubarak A, Wolters VM, Gmelig-Meyling FHJ, ten Kate FJW, Houwen RHJ. Tissue transglutaminase levels above $100 \mathrm{U} / \mathrm{mL}$ and celiac disease: A prospective study. World $\mathrm{J}$. Gastroenterol. 2012;18:4399-403.

[22] Moreno ML, Sousa C, Rodriguez A, Cebolla A. Detecting gluten peptides in human fluids, (2016), WO/2016/005643, Filed July 9, 2015, Published January 14, 2016.

[23] Bienvenu F, Anghel SI, Besson Duvanel C, Guillemaud J, Garnier L, Renosi F, Lachaux A, Bienvenu J. Early diagnosis of celiac disease in IgA deficient children: contribution of a pointof-care test. BMC Gastroenterol. 2014;14:186.

[24] Benkebil F, Combescure C, Anghel SI, Besson Duvanel C, Schäppi MG. Diagnostic accuracy of a new point-of-care screening assay for celiac disease, World J. Gastroenterol. 2013;19:5111-17.

[25] Wu H, Wallach M, Shimoni O. Challenges with Point-Of-Care Tests (POCT) for Celiac Disease. In Rodrigo L, Hernandez-Lahoz C, Editors. Celiac Disease - From the Bench to the Clinic. IntechOpen 2019 pp. 1-12.

[26] Soler M, Estevez MC, Moreno ML, Cebolla A, Lechuga LM. Label-free SPR detection of gluten peptides in urine for non-invasive celiac disease follow-up, Biosens. Bioelectron. 2016;79:158-64.

[27] Peláez EC, Estevez MC, Portela A, Salvador JP, Marco MP, Lechuga LM. Nanoplasmonic biosensor device for the monitoring of acenocoumarol therapeutic drug in plasma, Biosens. Bioelectron. 2018;119:149-55. 
[28] Morón B, Bethune MT, Comino I. Manyani H, Ferragud M, López MC, Cebolla A, Khosla C, Sousa C- Toward the assessment of food toxicity for celiac patients: Characterization of monoclonal antibodies to a main immunogenic gluten peptide. PLoS One. 2008;3:1-13.

[29] Comino I, Real A, Vivas S, Siglez M, Caminero A, Nistal E, Casqueiro J, Rodriguez-Herrera A, Cebolla A, Sousa C. Monitoring of gluten-free diet compliance in celiac patients by assessment of gliadin 33-mer equivalent epitopes in feces. Am. J. Clin. Nutr.2012; 95: 670-77.

[30] Real A, Comino I, Moreno ML, López-Casado MA, Lorite P, Torres MI, Cebolla A, Sousa C. Identification and in Vitro reactivity of celiac immunoactive peptides in an apparent glutenfree beer. PLoS One. 2014;9:12-14.

[31] De Vos K, Girones J, Popelka S, Schacht E, Baets R, Bienstman P. SOI optical microring resonator with poly(ethylene glycol) polymer brush for label-free biosensor applications. Biosens. Bioelectron. 2009;24:2528-33.

[32] Schilp S, Rosenhahn A, Pettitt ME, Bowen J, Callow ME, Callow J, Grunze M. Physicochemical properties of (ethylene glycol)-containing self-assembled monolayers relevant for protein and algal cell resistance. Langmuir. 2009;25:10077-82.

[33] Vega B, Calle A, Sánchez A, Lechuga LM, Ortiz AM, Armelles G, Rodríguez-Frade JM, Mellado M. Real-time detection of the chemokine CXCL12 in urine samples by surface plasmon resonance. Talanta. 2013;109:209-15.

[34] Comino I, Real A, Gil-Humanes J, Pistón F, de Lorenzo L, Moreno ML, López-Casado MA, Lorite P, Cebolla A, Torres MI, Barro F, Sousa C. Significant differences in coeliac immunotoxicity of barley varieties. Mol. Nutr. Food Res. 2012;56:1697-1707.

[35] Cebolla A, Moreno ML, Coto L, Sousa C. Gluten immunogenic peptides as standard for the evaluation of potential harmful prolamin content in food and human specimen, Nutrients. 2018;10:1-16.

[36] Sousa C, Comino I, Real A, Vivas S, Cebolla A. Determination of levels of immunogenic gluten peptides in human samples (2013). WO/2012/089868, Filed December 28, 2011, Published July, 5, 2012. 


\section{Figure Legends}

Figure 1. Photograph of the SPR biosensor platform showing the main units

Figure 2. Schematic representation of the biofunctionalization strategy and the 33-mer peptide detection assay

Figure 3. (A) Blocking effect of BSA $\left(10 \mathrm{mg} \mathrm{mL}^{-1}\right)$ to minimize non-specific adsorptions of urine. (B) Comparison of antibody signals in PBST, urine-PBST 1:1, and undiluted urine. [G12 $\mathrm{mAb}]=2$ $\mu \mathrm{g} \mathrm{mL} \mathrm{m}^{-1}$ and $[\mathrm{A} 1 \mathrm{mAb}]=5 \mu \mathrm{gL}^{-1}$ over surfaces blocked with BSA $\left(10 \mathrm{mg} \mathrm{mL}^{-1}\right)(\mathbf{C})$ Calibration curve for 33-mer peptide in PBST, urine-PBST 1:1 and urine $100 \%$ using [G12 $\mathrm{mAb}]=2 \mu \mathrm{g} \mathrm{mL}^{-1}$ and (D) using $[\mathrm{A} 1 \mathrm{mAb}]=5 \mu \mathrm{g} \mathrm{mL}^{-1}$. Each point represents the mean $\pm \mathrm{SD}$ of three replicates

Figure 4. Calibration curves in urine $100 \%$ obtained using: 33-mer peptide and G12 mAb (blue); 33mer peptide and $\mathrm{A} 1 \mathrm{mAb}$ (green); GIP extracted from urine and G12 mAb (purple); GIP and A1 mAb (orange). Each point represents the mean $\pm \mathrm{SD}$ of three replicates obtained with three different sensor chips

Figure 5. Correlation plot of GIP concentration of urine samples between iVYCHECK GIP Urine ${ }^{\mathrm{TM}}$ test and POC biosensor device. Slopes for assays using G12 mAb and A1 mAb are 0.96 and 1.03 respectively. (Each spot represents the mean \pm SD of triplicate measurements)

Figure 6. Levels of GIP in urine collected from two individuals determined with the G12 mAb biosensor during a controlled low gluten intake. The monitoring was done during a regular diet, followed by 2 days of GFD, and by a controlled gluten intake of 50, 150 and $250 \mathrm{mg}$ in the following days. Each spot represents the mean \pm SD of triplicate measurements. (Sample corresponding to a gluten intake of $250 \mathrm{mg}$ for Patient 2 was not collected) 


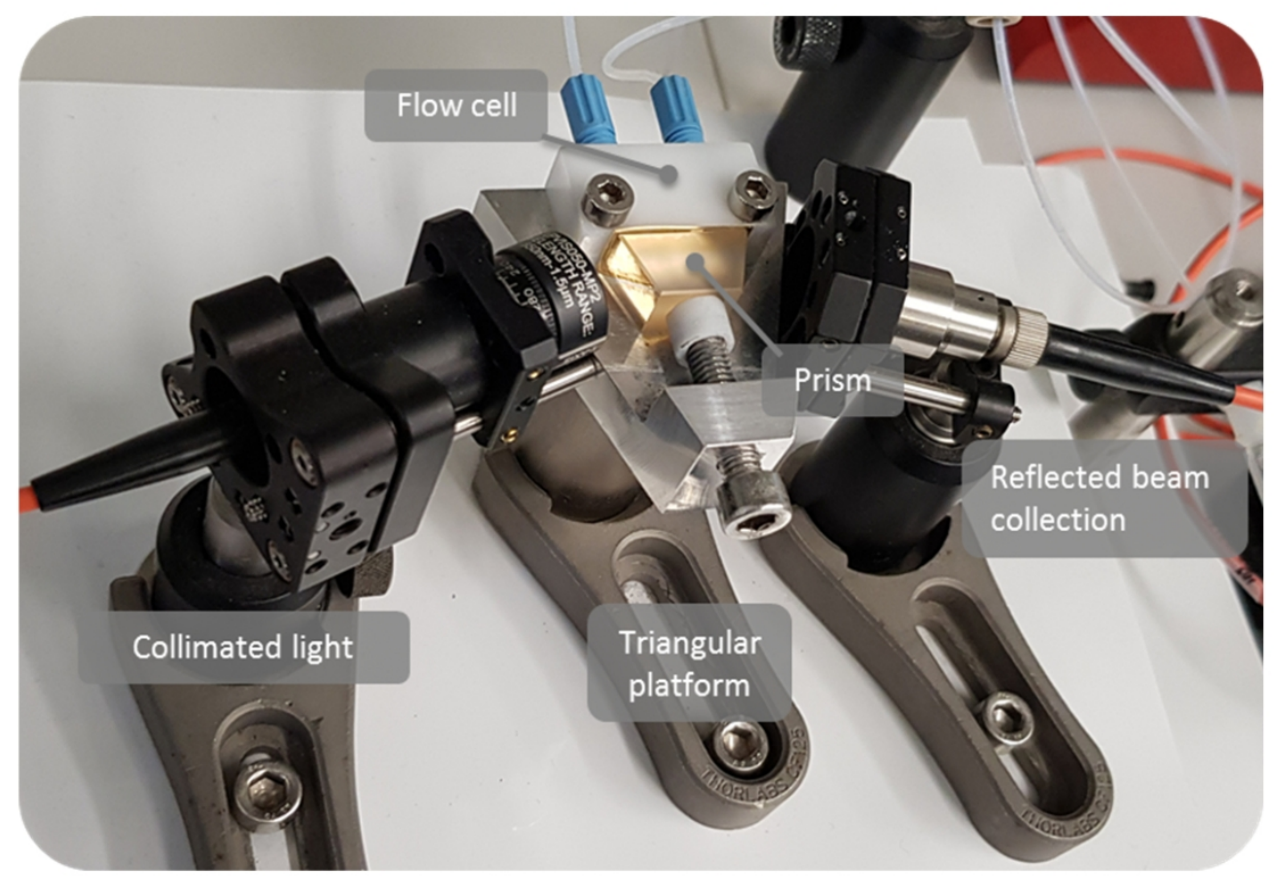

Photograph of the SPR biosensor platform showing the main units $99 \times 70 \mathrm{~mm}(300 \times 300 \mathrm{DPI})$ 
Schematic representation of the biofunctionalization strategy and the 33-mer peptide detection assay $160 \times 104 \mathrm{~mm}(300 \times 300 \mathrm{DPI})$ 

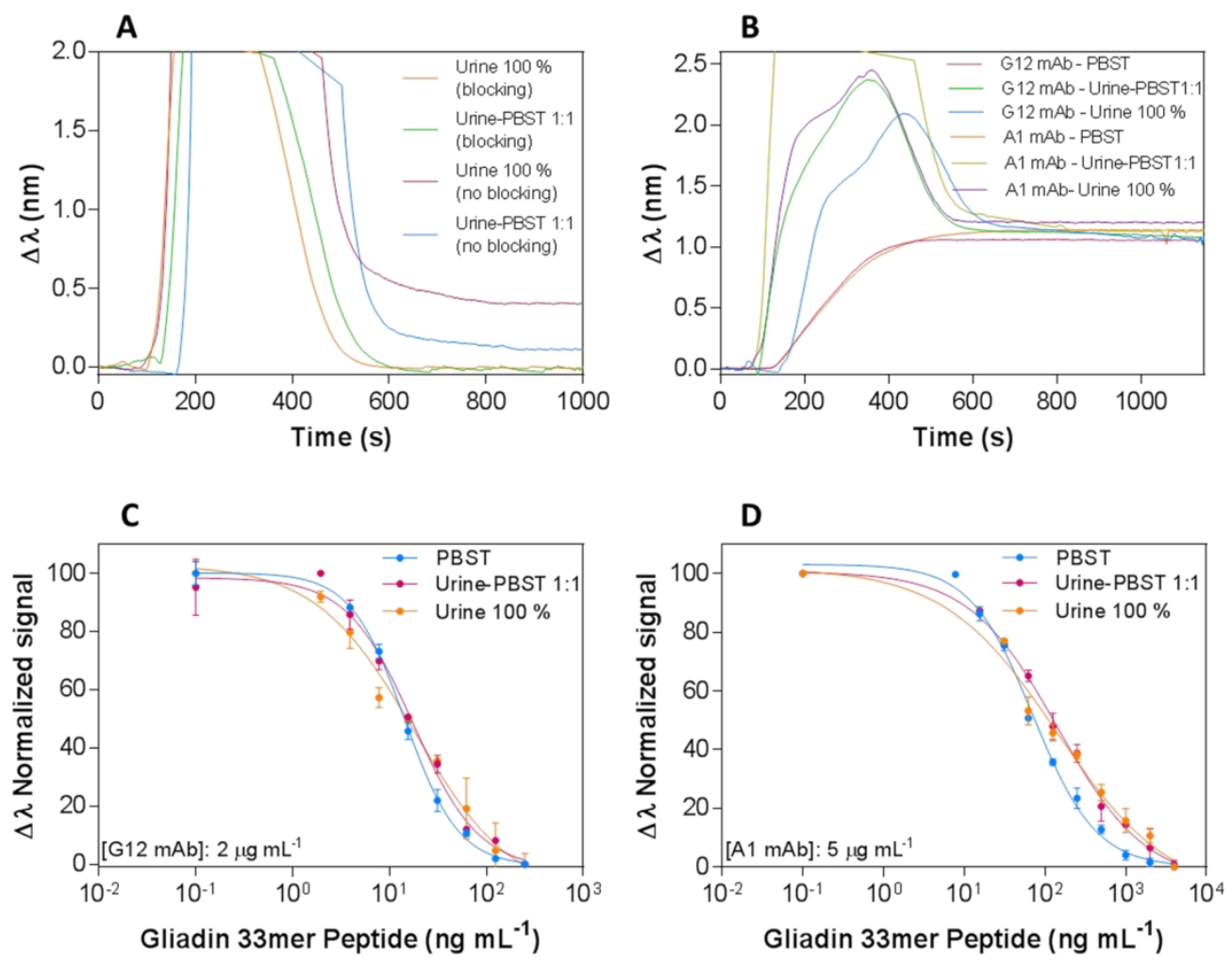

(A) Blocking effect of BSA (10 mg mL-1) to minimize non-specific adsorptions of urine. (B) Comparison of antibody signals in PBST, urine-PBST 1:1, and undiluted urine. [G12 mAb] $=2 \mu \mathrm{g} \mathrm{mL}-1$ and $[\mathrm{A} 1 \mathrm{mAb}]=5$ $\mu \mathrm{g} \mathrm{mL}-1$ over surfaces blocked with BSA $(10 \mathrm{mg} \mathrm{mL}-1)(C)$ Calibration curve for 33-mer peptide in PBST, urine-PBST 1:1 and urine $100 \%$ using [G12 mAb] $=2 \mu \mathrm{gL}-1$ and (D) using [A1 mAb] $=5 \mu \mathrm{g} \mathrm{mL}-1$. Each point represents the mean \pm SD of three replicates 


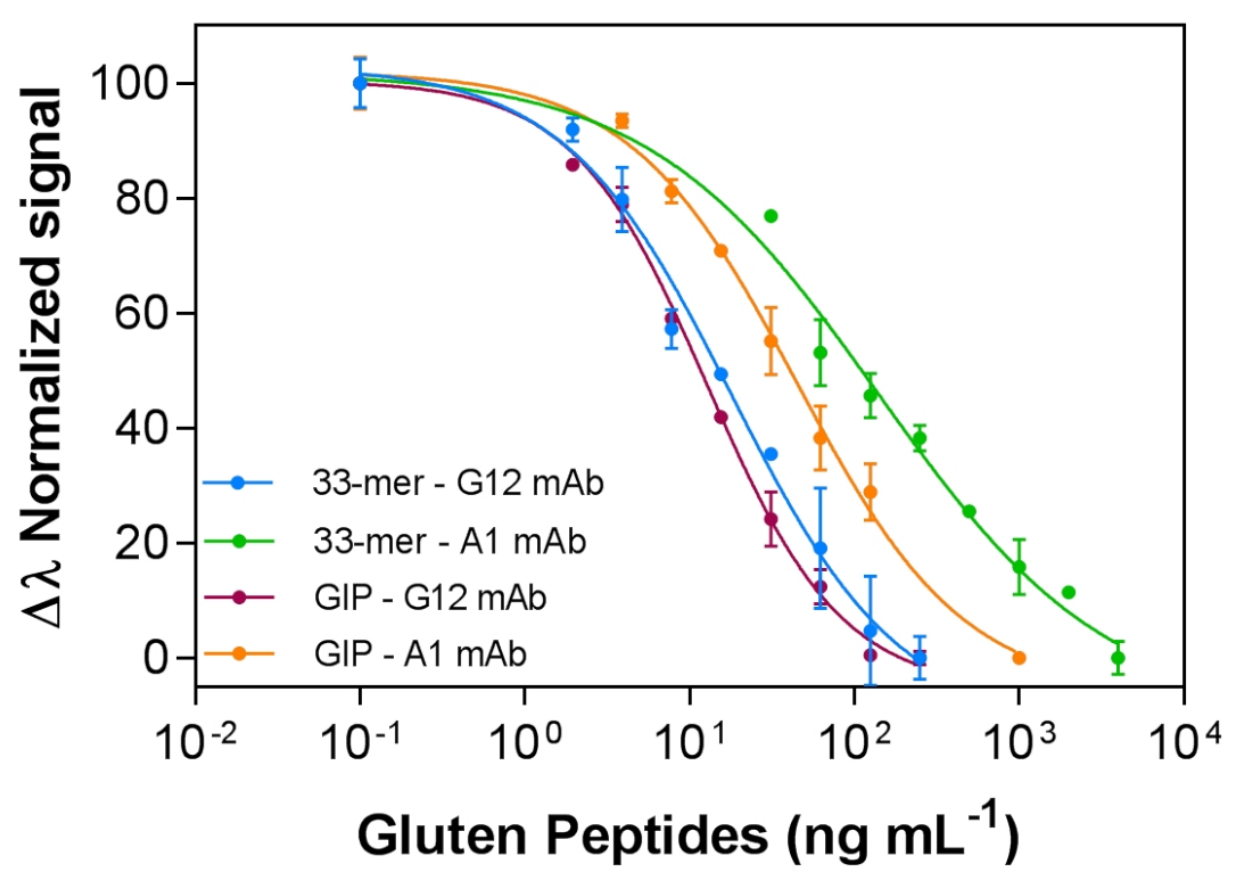

Calibration curves in urine $100 \%$ obtained using: 33-mer peptide and G12 mAb (blue); 33-mer peptide and A1 mAb (green); GIP extracted from urine and G12 mAb (purple); GIP and A1 mAb (orange). Each point represents the mean \pm SD of three replicates obtained with three different sensor chips

$99 \times 79 \mathrm{~mm}(300 \times 300 \mathrm{DPI})$ 


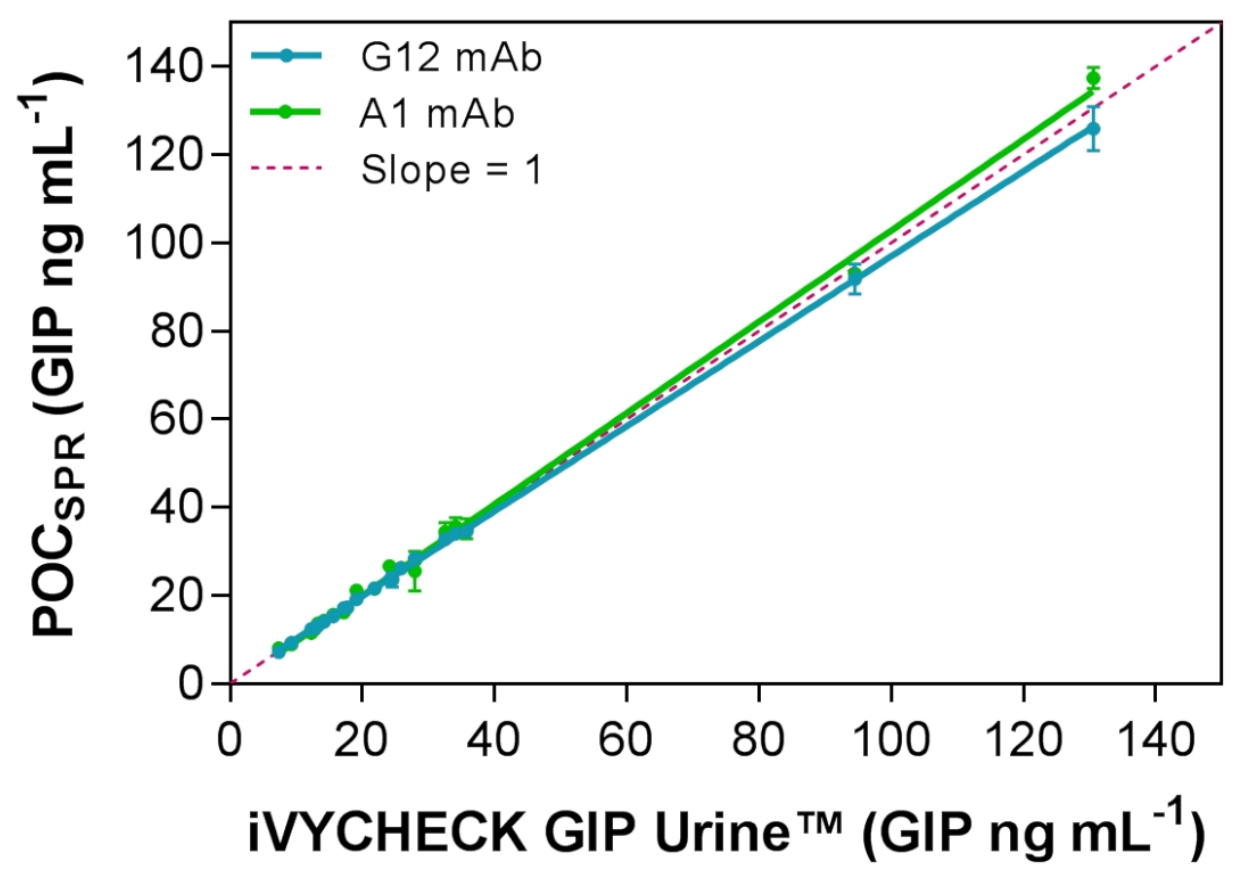

Correlation plot of GIP concentration of urine samples between iVYCHECK GIP Urine ${ }^{\mathrm{TM}}$ test and POC biosensor device. Slopes for assays using G12 mAb and A1 mAb are 0.96 and 1.03 respectively. (Each spot represents the mean $\pm \mathrm{SD}$ of triplicate measurements)

$99 \times 79 \mathrm{~mm}(300 \times 300 \mathrm{DPI})$ 
Levels of GIP in urine collected from two individuals determined with the G12 mAb biosensor during a controlled low gluten intake. The monitoring was done during a regular diet, followed by 2 days of GFD, and by a controlled gluten intake of 50,150 and $250 \mathrm{mg}$ in the following days. Each spot represents the mean \pm SD of triplicate measurements. (Sample corresponding to a gluten intake of $250 \mathrm{mg}$ for Patient 2 was not collected)

\author{
$99 \times 79 \mathrm{~mm}(300 \times 300 \mathrm{DPI})$
}




\title{
Supplementary Information
}

\section{A compact plasmonic biosensor device for the rapid and efficient monitoring of gluten free diet directly in human urine}

\author{
E. Cristina Peláez ${ }^{\mathrm{a}}$, M.-Carmen Estevez ${ }^{\mathrm{a}}$, Remedios Domínguez $^{\mathrm{b}}$, Carolina Sousa ${ }^{\mathrm{c}}$, Angel Cebolla ${ }^{\mathrm{b}}$ \\ and Laura M. Lechuga ${ }^{a}$
}

a Nanobiosensors and Bioanalytical Applications Group, Catalan Institute of Nanoscience and Nanotechnology (ICN2), CSIC, CIBER-BBN and BIST, Campus UAB Bellaterra, 08193 Barcelona, Spain.

b Biomedal S.L., Polígono Industrial Parque Plata, c/ Calzada Romana 40, 41900 Camas, Seville, Spain.

c Department of Microbiology and Parasitology, Faculty of Pharmacy, University of Seville, c/Profesor García González, S/N, 41012 Seville, Spain

*Corresponding author: M.-Carmen Estevez: mcarmen.estevez@icn2.cat 


\section{Chemicals and immunoreagents}

Acetone, ethanol absolute and isopropanol were purchased from Panreac-Applichem (Barcelona, Spain). Alkanethiols: $\mathrm{HS}_{-} \mathrm{C}_{11}-(\mathrm{EG})_{6}-\mathrm{O}-\mathrm{CH}_{2}-\mathrm{COOH}\left(\mathrm{MW}: 526.73 \mathrm{~g} \mathrm{~mol}^{-1}\right)$ and $\mathrm{HS}_{-} \mathrm{C}_{11}-(\mathrm{EG})_{4}-\mathrm{OH}$ (MW: $380.48 \mathrm{~g} \mathrm{~mol}^{-1}$ ) were acquired from Prochimia (Poland). Bovine serum albumin (BSA), 1ethyl-3(3-dimethylaminopropyl)carbodiimide hydrochloride (EDC), N-hydroxysulfosuccinimide (NHS), ethanolamine hydrochloride, $\mathrm{NaOH}$, centrifugal filters Amicon Ultra $10 \mathrm{kDa}(0.5 \mathrm{~mL}$ Ultracel membrane of regenerated cellulose 10000 MWCO Millipore) and all reagents for buffers preparation were purchased from Sigma-Aldrich (Steinhem, Germany). Buffers employed were the following: MES (2-(-N-morpholino)ethanesulfonic acid $100 \mathrm{mM}$ and $500 \mathrm{mM} \mathrm{NaCl}, \mathrm{pH}$ 5.5), acetate buffer (10 $\mathrm{mM} \mathrm{pH}$ from 4.0 to 5.5), PBS ( $1 \mathrm{mM}$ phosphate, $137 \mathrm{mM} \mathrm{NaCl}, 2.7 \mathrm{mM} \mathrm{KCl}, \mathrm{pH} 7.4)$, PBST (PBS with $0.5 \%$ Tween 20), and PBST-BSA (PBST with BSA $10 \mathrm{mg} \mathrm{mL}^{-1}$ ). Monoclonal antibodies G12 and $\mathrm{A} 1$, prolamin working group (PWG) gliadin and $\alpha 2$-gliadin 33-mer peptide (33-mer) were provided by Biomedal S.L. (Seville, Spain).

\section{SPR biosensor device and operation principle}

For the SPR set-up, optical components are attached to a triangular platform with a fix optimal incidence angle of $70^{\circ}$. Gold sensing chip is clamped between the fluid cell $(4 \mu \mathrm{L})$ and a trapezoidal prism. A collimated halogen light (HL-2000, Ocean Optics, USA) hits the sensing area, set in transverse-magnetic (TM) polarization mode. The reflected light is collected by a fiber-coupled to a CCD spectrometer (Ocean Optics, Jazz, Module, USA). A syringe pump connected to the cell continuously delivers fluid over the sensor chip. Samples are added through a loop $(200 \mu \mathrm{L})$ connected to a 6-port injection valve. A homemade readout software (National Instruments, Labview, USA) is used for real-time monitoring of the shift of the plasmonic resonance peak at $\lambda_{\text {SPR }}(675 \mathrm{~nm})$ via polynomial fit (see Fig. S1A in SI). Reflectivity spectra are acquired every 3 ms and 300 spectra are averaged to generate the resonant spectrum. Chemical interactions over the sensing area cause a RI increase, which results in a redshift of the position of the resonance peak $\left(\Delta \lambda_{\text {SPR }}\right)$, whereas the desorption events result in blueshift. These displacements can be monitored and related to the concentration of the analyte to be evaluated (see Fig S1B in SI). Prior to surface functionalization, sensor chips were cleaned by successive heating and sonication cycles for $1 \mathrm{~min}$ with acetone and isopropanol. Then, they were dried with $\mathrm{N} 2$ stream and placed in a UV-O3 cleaner (BioForce Nanoscience, USA) for $30 \mathrm{~min}$. Finally, chips were rinsed with ethanol and dried with N2 stream.

\section{BSA blocking step. Optimization and regeneration conditions of the sensor chip}

In the case of evaluating urine, it was necessary to perform a previous blocking step with BSA in PBST to eliminate non-specific adsorptions from the urine matrix. The injection time of BSA in PBST was evaluated at a flow rate of $25 \mu \mathrm{L} \mathrm{min}^{-1}$ during $0,30,60,120,180,240$ and $300 \mathrm{~s}$. Fig. S6A in SI, shows signals of urine-PBST 1:1 and urine $100 \%$ for each injection time. In all cases, signal obtained after adding BSA is very similar (red line). Applying blocking buffer during $60 \mathrm{~s}$, nonspecific adsorptions for urine-PBST 1:1 are removed completely. In case of urine $100 \%$, it was necessary an injection time of $120 \mathrm{~s}$. These injection times were therefore selected depending on the media employed to evaluate the calibration curve (urine $50 \%$ or $100 \%$ ). The blocking capability of this approach was studied by successive BSA-urine $100 \%$ regeneration cycles (i.e. with neither antibody nor analyte) over the coated-PWG gliadin sensor chip. Fig. S6B in SI shows signals of urine $100 \%$. In each injection, signal increases due to the bulk effects from components of urine and decays to the baseline signal (i.e. no net adsorption on the sensor surface). This is observed for at least 38 cycles without detecting significant damage or non-efficient blocking of the sensor surface. The same experiment was performed but adding the antibody to the urine $100 \%$. Fig. S6C and D in SI show the 
signals obtained from antibodies G12 $\left(2 \mu \mathrm{g} \mathrm{mL}^{-1}\right)$ and A1 $\left(5 \mu \mathrm{g} \mathrm{mL}^{-1}\right)$ in urine $100 \%$, respectively. Signals are high reproducible and stable until the cycle 17 for G12 and cycle 19 for A1, respectively, when they start decreasing. This might be related to a loss of effectiveness of the blocking step or the degradation of the immobilized layer due to the successive addition of proteins, complex media and basic conditions.

A

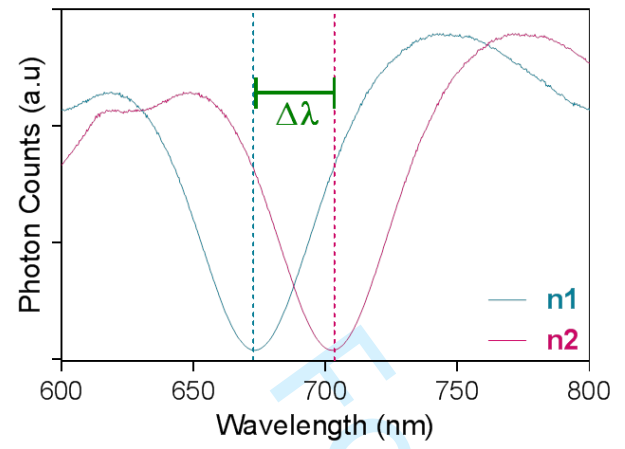

\section{B}

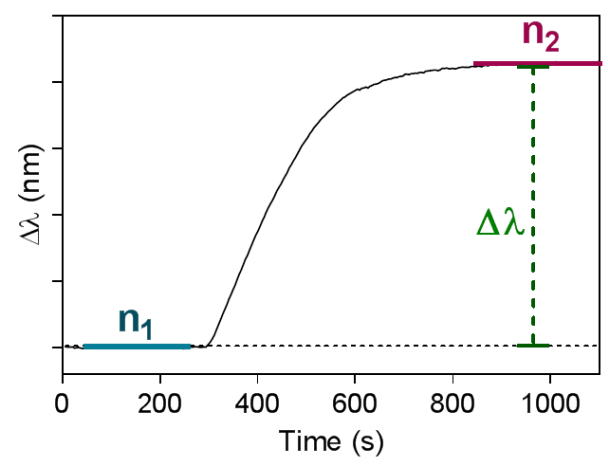

Figure S1. (A) Spectra showing wavelength displacement of the resonance peak $\left(\Delta \lambda_{\mathrm{SPR}}\right)$ to refractive index changes (n2>n1). (B) Real-time monitoring of wavelength displacements $(\Delta \lambda(\mathrm{nm}) v s$. time (s)). 

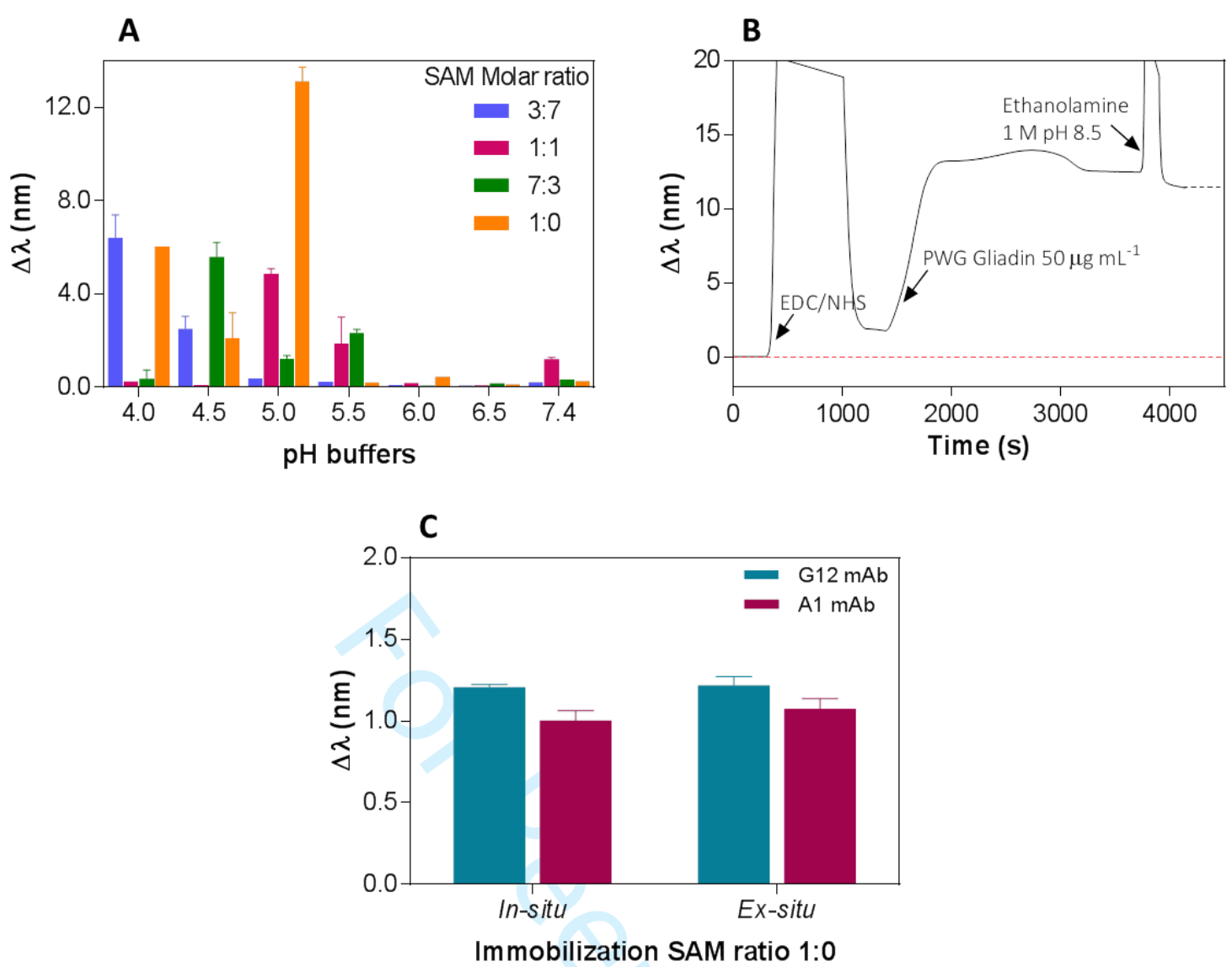

Figure S2. (A) Optimization of PWG gliadin $\left(50 \mu \mathrm{g} \mathrm{mL} \mathrm{mL}^{-1}\right)$ immobilization with EG-COOH:EG-OH thiols at different ratios $(3: 7,1: 1,7: 3,1: 0)$ and at different $\mathrm{pH}$ conditions (from 4.0 to 7.4 ) (B) Realtime sensorgram showing in-situ immobilization steps in a SAM ratio 1:0 (carboxylic groups activation, PWG gliadin immobilization $(50 \mu \mathrm{g} \mathrm{mL}-1)$ in acetate buffer $\mathrm{pH} 5.0$ and blocking of remaining activated groups. (C) Comparison of the antibodies signals of G12 $\left(2 \mu \mathrm{g} \mathrm{mL}^{-1}\right)$ and A1 (5 $\mu \mathrm{g} \mathrm{mL}^{-1}$ ) for in-situ and ex-situ immobilization process, respectively.
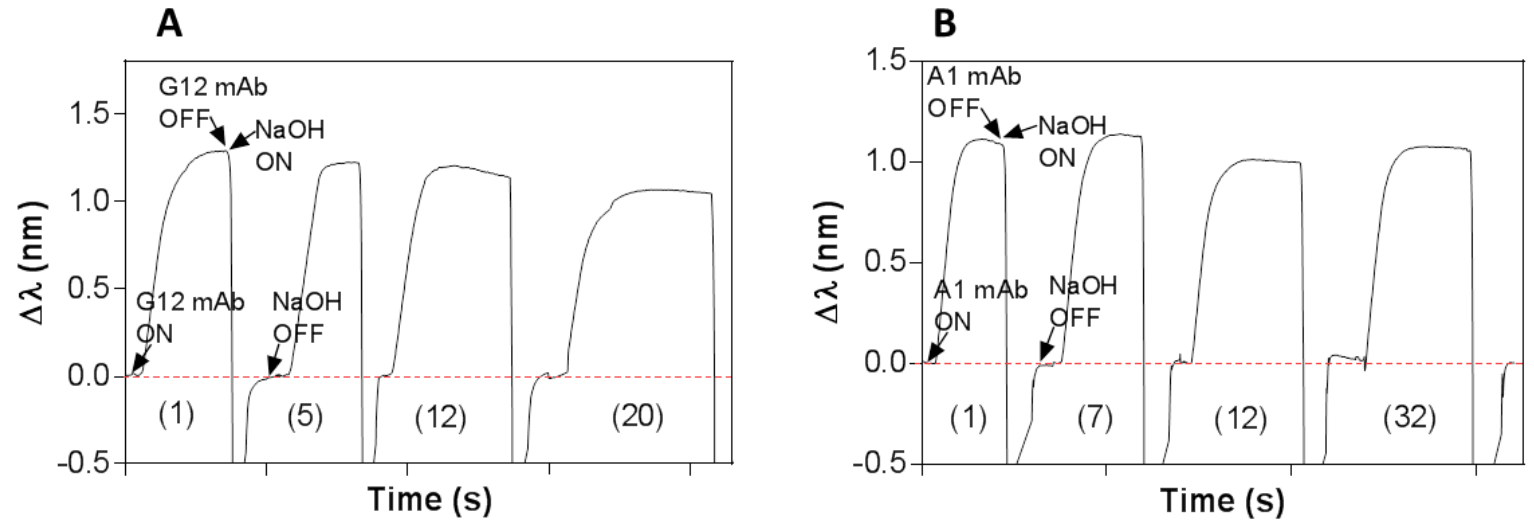

Figure S3. Sensorgrams showing the $\Delta \lambda_{\text {SPR }}$ for throughout successive measurement (in PBST) and regeneration cycles (in $\mathrm{NaOH} 5 \mathrm{mM}$ ) of (A) $\mathrm{G} 12 \mathrm{mAb}\left(2 \mu \mathrm{g} \mathrm{mL}^{-1}\right)$; (B) A1 mAb $\left(5 \mu \mathrm{g} \mathrm{mL}^{-1}\right)$. 


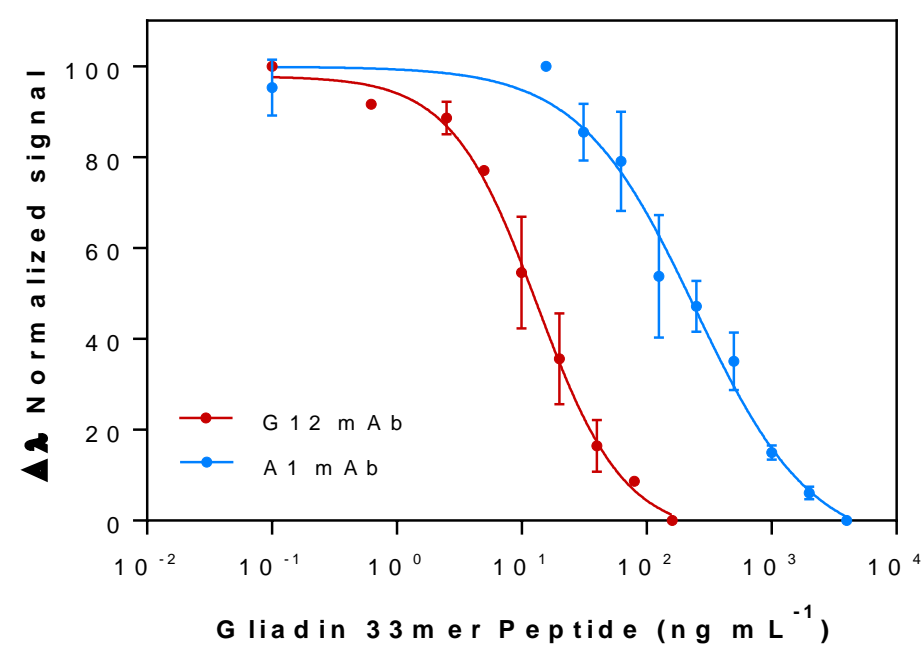

Figure S4. Calibration curves of intra-assays of $\alpha 2$-gliadin 33-mer peptide detection by indirect competitive immunoassay in PBST using the antibodies G12 mAb (red curve) and A1 mAb (blue curve). Each data represents the mean \pm SD of two replicates. (Intra-assays are two complete assays with the same biofunctionalized chip).

A

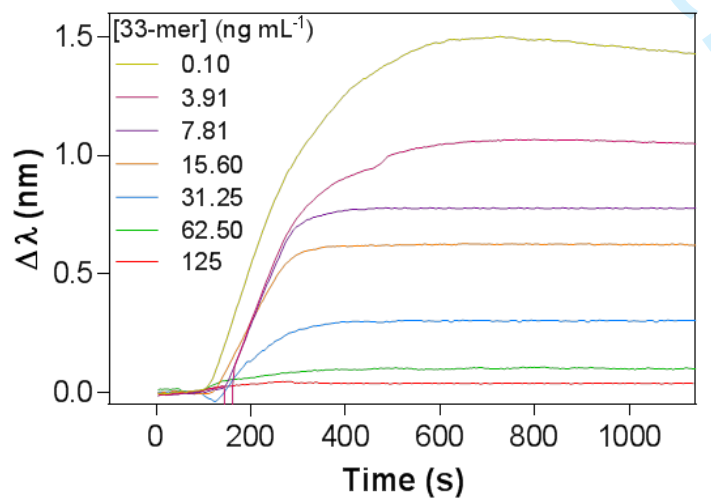

B

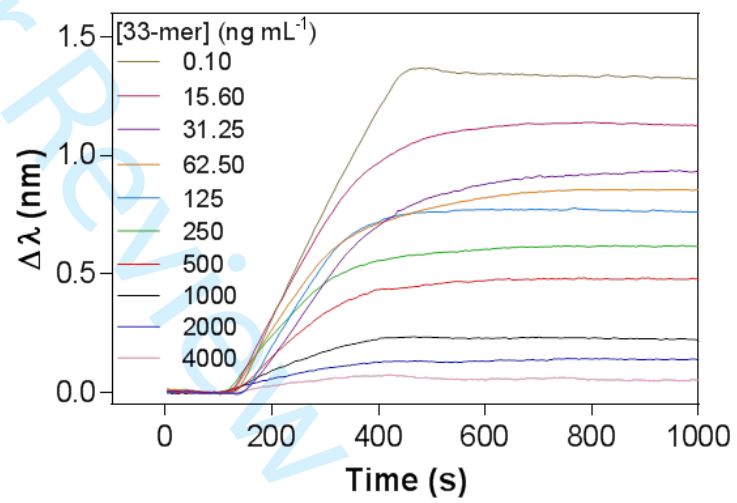

Figure S5. Real-time sensorgram of different $\alpha 2$-gliadin 33-mer peptide concentrations in PBST buffer using: (A) G12 mAb and (B) A1 mAb. 
A

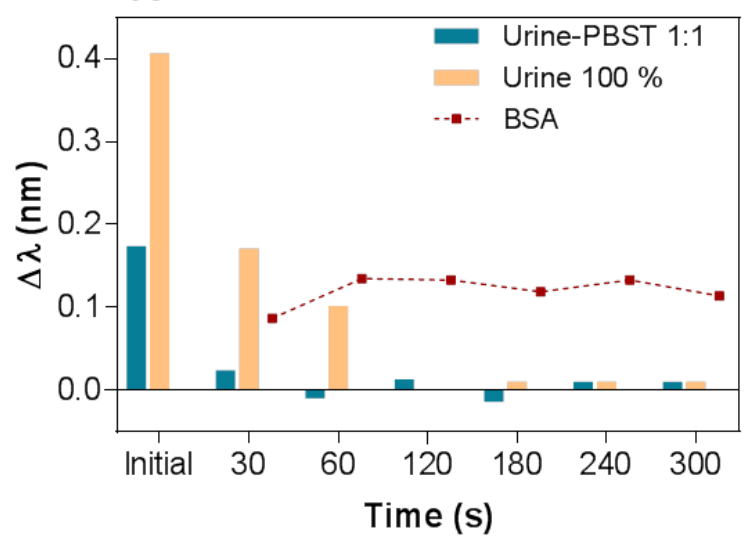

C

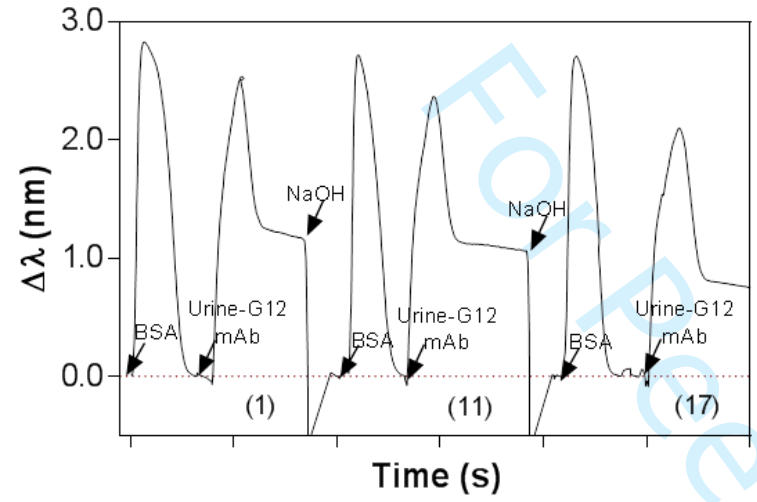

B

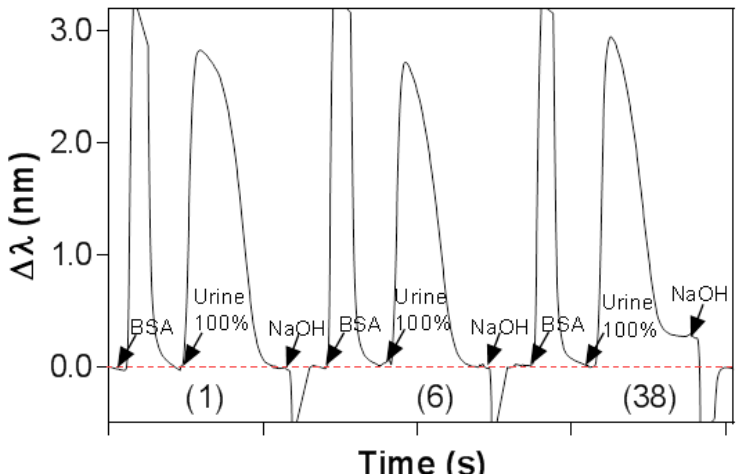

Time (s)

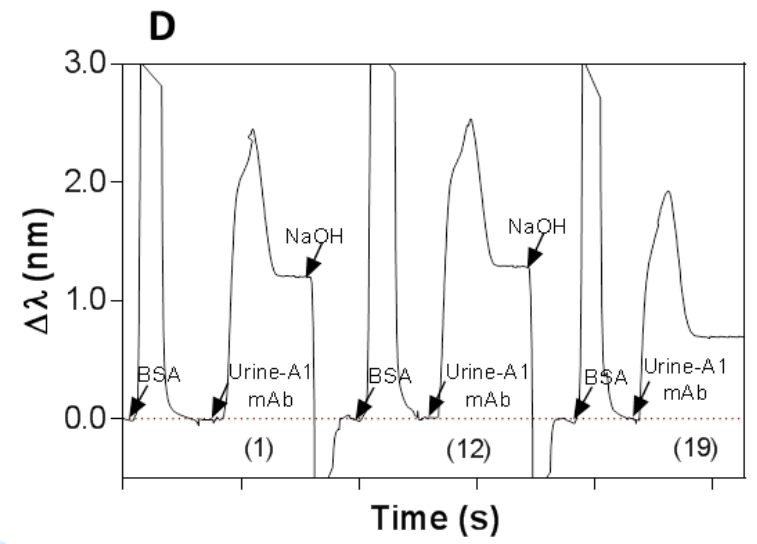

Figure S6. (A) Effect of the blocking time with BSA (10 mg mL $\mathrm{mL}^{-1}$ in PBST) on the removal of nonspecific adsorptions from urine $100 \%$ and urine-PBST 1:1. Corresponding signal resultant from the adsorption of the BSA blocking layer is shown for each time of injection (B) $\Delta \lambda$ signals obtained throughout successive cycles of blocking (BSA $\left.10 \mathrm{mg} \mathrm{mL}^{-1}\right)$, urine $(100 \%)$ and regeneration $(\mathrm{NaOH}$ $5 \mathrm{mM}$ ). Neither antibody nor target analytes are present in the solutions. (C) $\Delta \lambda$ signals obtained throughout successive cycles of blocking (BSA $10 \mathrm{mg} \mathrm{mL}^{-1}$ ), urine (100\%) containing G12 mAb (2 $\left.\mu \mathrm{g} \mathrm{mL} \mathrm{m}^{-1}\right)$ ) and regeneration $(\mathrm{NaOH} 5 \mathrm{mM}$ ); (D) $\Delta \lambda$ signals obtained throughout successive cycles of blocking (BSA $\left.10 \mathrm{mg} \mathrm{mL}^{-1}\right)$, urine $\left(100 \%\right.$ containing A1 mAb $\left.\left(5 \mu \mathrm{g} \mathrm{mL}^{-1}\right)\right)$ and regeneration $(\mathrm{NaOH}$ $5 \mathrm{mM})$.
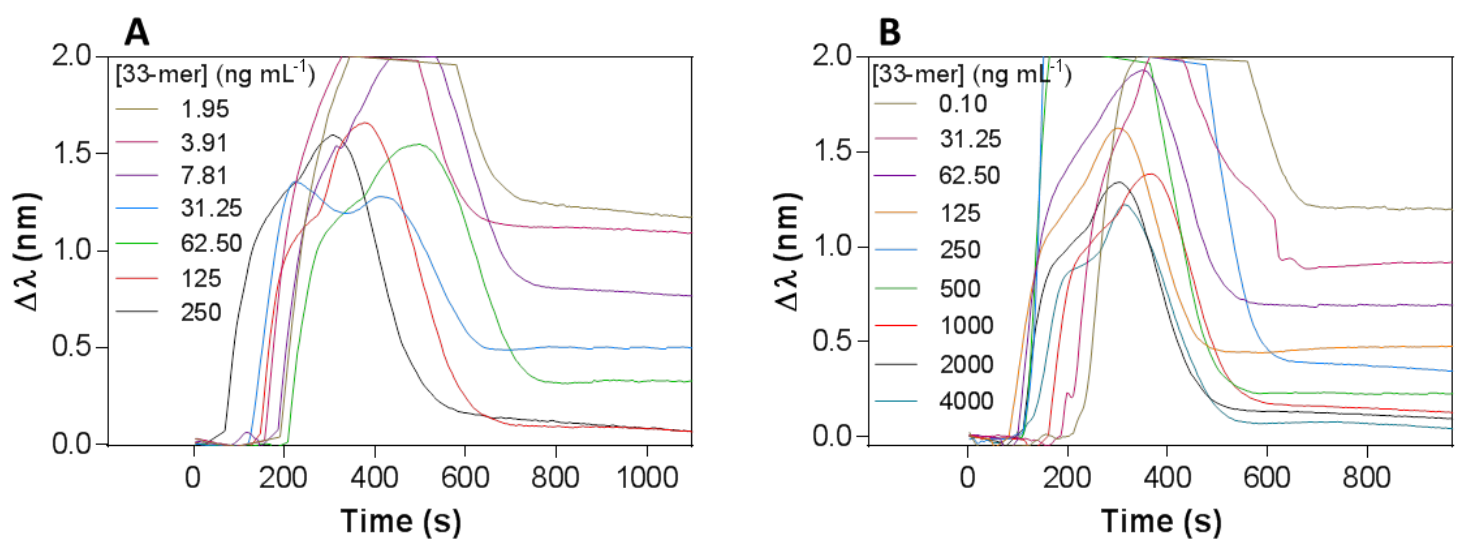

Figure S7. Real-time sensorgrams for different $\alpha 2$-gliadin 33-mer peptide concentrations prepared in urine $100 \%$ using: (A) G12 mAb and (B) A1 mAb. 
A

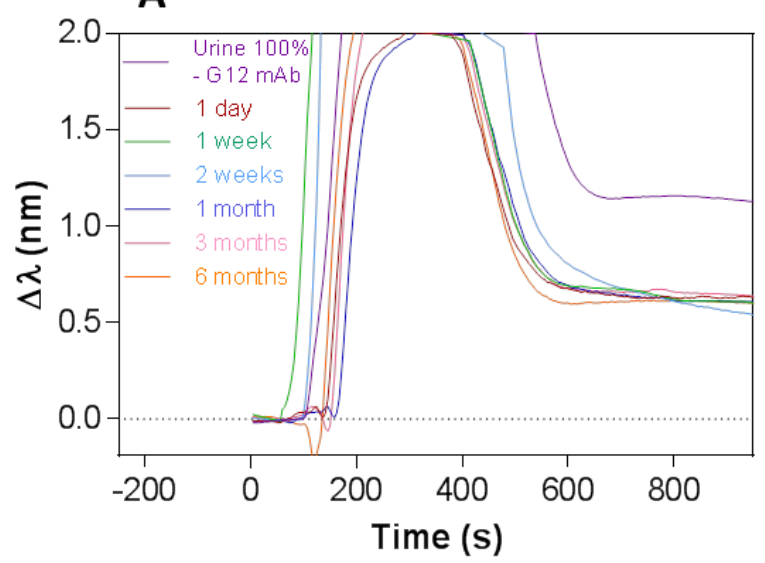

B

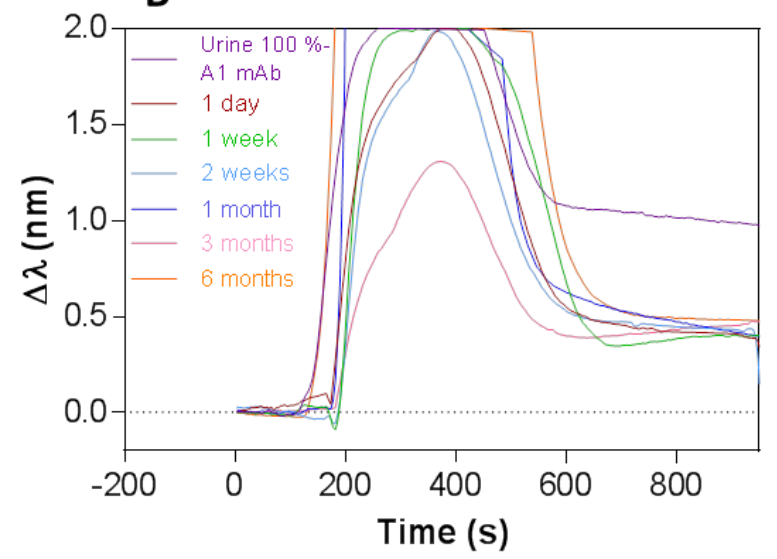

Figure S8. Stability of chips over time. Real time sensorgrams of urine samples spiked with 33-mer peptide obtained in sensor chips stored different periods of time using (A) [G12] $=2 \mu \mathrm{g} \mathrm{mL}^{-1}$ and [33mer] $=15.6 \mathrm{ng} \mathrm{mL}^{-1}$; (B) $[\mathrm{A} 1]=5 \mu \mathrm{g} \mathrm{mL}^{-1}$ and $[33-\mathrm{mer}]=125 \mathrm{ng} \mathrm{mL}^{-1}$. A representative sensorgram for the maximum signal (i.e. only antibody, zero analyte concentration) in urine $100 \%$ is shown for each antibody (purple line). 
Table S1. Intra-assay and inter-assay variability for the G12 and A1-based indirect competitive immunoassays for the detection of 33-mer peptide in PBST

\begin{tabular}{|c|c|c|c|c|c|}
\hline \multirow{2}{*}{ Antibodies } & \multirow{2}{*}{ Parameter } & \multicolumn{2}{|c|}{ Intra-assay ${ }^{a}$} & \multicolumn{2}{|c|}{ Inter-assay $^{b}$} \\
\hline & & Mean \pm SD & $\mathrm{CV}(\%)$ & Mean \pm SD & $\mathrm{CV}(\%)$ \\
\hline \multirow{6}{*}{$\mathrm{G} 12 \mathrm{mAb}$} & $\Delta \lambda_{\max }(\mathrm{nm})$ & $1.19 \pm 0.08$ & 6.72 & $1.17 \pm 0.07$ & 5.98 \\
\hline & $\mathrm{LOD}\left(\mathrm{IC}_{90}\right)\left(\mathrm{ng} \mathrm{mL}^{-1}\right)$ & $2.13 \pm 0.10$ & 4.69 & $2.43 \pm 0.81$ & 33.3 \\
\hline & $\mathrm{IC}_{50}(\mathrm{ng} \mathrm{mL}-1)$ & $12.6 \pm 2.98$ & 23.7 & $13.4 \pm 3.21$ & 24.0 \\
\hline & $\mathrm{LOQ}\left(\mathrm{IC}_{80}\right)\left(\mathrm{ng} \mathrm{mL}^{-1}\right)$ & $4.42 \pm 0.81$ & 18.3 & $4.55 \pm 1.08$ & 23.7 \\
\hline & $\mathrm{IC}_{20}\left(\mathrm{ng} \mathrm{mL}^{-1}\right)$ & $33.3 \pm 5.88$ & 17.7 & $37.0 \pm 8.10$ & 21.9 \\
\hline & Slope & $-1.43 \pm 0.04$ & 2.80 & $-1.25 \pm 0.16$ & 12.8 \\
\hline \multirow{6}{*}{$\mathrm{A} 1 \mathrm{mAb}$} & $\Delta \lambda_{\max }(\mathrm{nm})$ & $0.94 \pm 0.07$ & 7.45 & $0.98 \pm 0.12$ & 12.2 \\
\hline & $\mathrm{LOD}\left(\mathrm{IC}_{90}\right)\left(\mathrm{ng} \mathrm{mL}^{-1}\right)$ & $21.8 \pm 12.4$ & 57.0 & $34.2 \pm 17.3$ & 50.7 \\
\hline & $\mathrm{IC}_{50}\left(\mathrm{ng} \mathrm{mL}^{-1}\right)$ & $219.7 \pm 70.4$ & 32.1 & $219.7 \pm 34.9$ & 15.9 \\
\hline & $\mathrm{LOQ}\left(\mathrm{IC}_{80}\right)\left(\mathrm{ng} \mathrm{mL}^{-1}\right)$ & $53.4 \pm 15.2$ & 28.5 & $55.8 \pm 22.9$ & 41.1 \\
\hline & $\mathrm{IC}_{20}\left(\mathrm{ng} \mathrm{mL}^{-1}\right)$ & $777.3 \pm 231$ & 29.7 & $727.3 \pm 122$ & 16.8 \\
\hline & Slope & $-1.01 \pm 0.07$ & 6.93 & $-1.04 \pm 0.37$ & 35.6 \\
\hline
\end{tabular}

a 2 complete curves obtained with the same biofunctionalized chip

b 3 complete curves obtained with 3 different biofunctionalized chips

Table S2. Inter-assay ${ }^{\mathrm{a}}$ variability for the G12 and A1-based indirect competitive immunoassays in $100 \%$ urine for the detection of 33-mer peptide and GIP

\begin{tabular}{|c|c|c|c|c|c|c|}
\hline \multirow{2}{*}{ Target } & \multirow{2}{*}{ Sample } & \multirow{2}{*}{ Parameter } & \multicolumn{2}{|c|}{ G12 mAb } & \multicolumn{2}{|c|}{ A1 mAb } \\
\hline & & & Mean \pm SD & CV (\%) & Mean \pm SD & CV (\%) \\
\hline \multirow{6}{*}{ 33-mer } & \multirow{6}{*}{$\begin{array}{l}\text { Urine } \\
100 \%\end{array}$} & $\Delta \lambda_{\max }(\mathrm{nm})$ & $1.26 \pm 0.06$ & 4.76 & $0.85 \pm 0.01$ & 1.18 \\
\hline & & $\mathrm{LOD}\left(\mathrm{ng} \mathrm{mL}^{-1}\right)$ & $1.65 \pm 0.03$ & 1.82 & $4.70 \pm 1.36$ & 28.9 \\
\hline & & $\mathrm{IC}_{50}\left(\mathrm{ng} \mathrm{mL} \mathrm{L}^{-1}\right)$ & $15.2 \pm 2.21$ & 14.5 & $111.8 \pm 12.1$ & 10.8 \\
\hline & & LOQ (ng mL $\left.\mathrm{mL}^{-1}\right)$ & $3.62 \pm 0.22$ & 6.08 & $14.7 \pm 3.20$ & 21.8 \\
\hline & & $\mathrm{IC}_{20}\left(\mathrm{ng} \mathrm{mL}^{-1}\right)$ & $56.2 \pm 13.3$ & 23.7 & $702.3 \pm 110$ & 15.7 \\
\hline & & Slope & $-0.87 \pm 0.07$ & 8.05 & $-0.62 \pm 0.07$ & 11.3 \\
\hline \multirow{6}{*}{ GIP } & \multirow{6}{*}{$\begin{array}{l}\text { Urine } \\
100 \%\end{array}$} & $\Delta \lambda_{\max }(\mathrm{nm})$ & $1.18 \pm 0.01$ & 0.85 & $0.93 \pm 0.04$ & 4.30 \\
\hline & & LOD $\left(n g \mathrm{~mL}^{-1}\right)$ & $1.67 \pm 0.09$ & 5.39 & $4.02 \pm 1.15$ & 28.6 \\
\hline & & $\mathrm{IC}_{50}\left(\mathrm{ng} \mathrm{mL}^{-1}\right)$ & $11.5 \pm 0.61$ & 5.30 & $41.2 \pm 4.74$ & 11.5 \\
\hline & & LOQ (ng $\left.\mathrm{mL}^{-1}\right)$ & $3.44 \pm 0.03$ & 0.87 & $9.15 \pm 1.23$ & 13.4 \\
\hline & & $\mathrm{IC}_{20}\left(\mathrm{ng} \mathrm{mL} L^{-1}\right)$ & $35.4 \pm 3.00$ & 8.47 & $172 \pm 43.3$ & 25.2 \\
\hline & & Slope & $-1.11 \pm 0.06$ & 5.40 & $-0.86 \pm 0.17$ & 19.8 \\
\hline
\end{tabular}

a 3 complete curves obtained with 3 different biofunctionalized chips 